\title{
The geospace response to variable inputs from the lower atmosphere: a review of the progress made by Task Group 4 of CAWSES-II
}

\author{
Jens Oberheide ${ }^{1 *}$, Kazuo Shiokawa ${ }^{2}$, Subramanian Gurubaran ${ }^{3}$, William E Ward ${ }^{4}$, Hitoshi Fujiwara ${ }^{5}$,
} Michael J Kosch ${ }^{6,7,8}$, Jonathan J Makela ${ }^{9}$ and Hisao Takahashi ${ }^{10}$

\begin{abstract}
The advent of new satellite missions, ground-based instrumentation networks, and the development of whole atmosphere models over the past decade resulted in a paradigm shift in understanding the variability of geospace, that is, the region of the atmosphere between the stratosphere and several thousand kilometers above ground where atmosphere-ionosphere-magnetosphere interactions occur. It has now been realized that conditions in geospace are linked strongly to terrestrial weather and climate below, contradicting previous textbook knowledge that the space weather of Earth's near space environment is driven by energy injections at high latitudes connected with magnetosphere-ionosphere coupling and solar radiation variation at extreme ultraviolet wavelengths alone. The primary mechanism through which energy and momentum are transferred from the lower atmosphere is through the generation, propagation, and dissipation of atmospheric waves over a wide range of spatial and temporal scales including electrodynamic coupling through dynamo processes and plasma bubble seeding. The main task of Task Group 4 of SCOSTEP's CAWSES-II program, 2009 to 2013, was to study the geospace response to waves generated by meteorological events, their interaction with the mean flow, and their impact on the ionosphere and their relation to competing thermospheric disturbances generated by energy inputs from above, such as auroral processes at high latitudes. This paper reviews the progress made during the CAWSES-II time period, emphasizing the role of gravity waves, planetary waves and tides, and their ionospheric impacts. Specific campaign contributions from Task Group 4 are highlighted, and future research directions are discussed.
\end{abstract}

Keywords: Geospace; Thermosphere; Ionosphere; Tides; Planetary waves; Gravity waves; Traveling ionospheric disturbances; Traveling atmospheric disturbances

\section{Introduction}

The space weather of Earth's upper neutral and ionized atmosphere is strongly influenced by energy injections at high latitudes connected with magnetosphere-ionosphere coupling and solar radiation variability at extreme ultraviolet wavelengths. A variety of new evidence obtained over the past few years now demonstrates unequivocally that the geospace environment also owes a substantial amount of its variability to waves forced in the lower parts of Earth's atmosphere, that is, the troposphere and stratosphere. This paradigm shift in understanding the causes of

\footnotetext{
* Correspondence: joberhe@clemson.edu

'Department of Physics and Astronomy, Clemson University, Clemson, SC 29634-0978, USA

Full list of author information is available at the end of the article
}

geospace variability was made possible by the advent of satellite missions like Imager for Magnetopause-to-Aurora Global Exploration (IMAGE) (Burch 2000), Thermosphere Ionosphere Mesosphere Energetics and Dynamics (TIMED) (Yee et al. 1999), CHAllenging Minisatellite Payload (CHAMP) (Reigber et al. 2006), Gravity Recovery and Climate Experiment (GRACE) (Tapley et al. 2004), and Constellation Observing System for Meteorology (COSMIC) (Anthes et al. 2008), advanced ground-based observing capabilities like Poker Flat Advanced Modular Incoherent Scatter Radar (PFISR) (e.g., Nicolls and Heinselman 2007) and airglow observing networks (e.g., Shiokawa et al. 2009; Makela et al. 2009), and the development of 'whole atmosphere' general circulation models from the ground to the ionosphere such as Whole Atmosphere Community 
Climate Model - thermosphere extension (WACCM-X) (Liu et al. 2010a), Whole Atmosphere Model (WAM)/ Coupled Thermosphere Ionosphere Plasmasphere Electrodynamics Model (CTIPe) (Fuller-Rowell et al. 2010), and ground-to-topside model of Atmosphere and Ionosphere for Aeronomy (GAIA) (Jin et al. 2011). See the list of abbreviations at the end of the paper. It is by now without dispute that geospace owes much of its longitudinal, seasonal-latitudinal, and day-to-day variability to meteorological weather processes in the troposphere and stratosphere (e.g., Immel et al. 2006; Forbes et al. 2006; Oberheide et al. 2006b; Hagan et al. 2007; Goncharenko et al. 2010; Fritts and Lund 2011; Maute et al. 2012; and references therein). The primary mechanism through which energy and momentum are transferred from the lower atmosphere is through the propagation and dissipation of atmospheric waves, including electrodynamic coupling through dynamo processes and instability seeding. Table 1 summarizes the basic characteristics of the three most important classes of atmospheric waves: gravity waves (GWs), atmospheric tides, and planetary waves (PWs).

CAWSES-II Task Group 4 (TG4; What is the geospace response to variable inputs from the lower atmosphere?) was therefore charged to elucidate the dynamical coupling from the low and middle atmosphere to the geospace (i.e., the upper atmosphere, ionosphere, and magnetosphere), for various wave frequencies and scales, and for equatorial, middle, and high latitudes. As meeting the challenge clearly requires a systems approach involving experimentalists, data analysts, and modelers from different communities, an essential part of TG4 was to encourage interactions between atmospheric scientists and plasma scientists on all occasions. To distinguish geospace variability due to solar and magnetospheric driving from above from processes propagating from below, and in order to dissect the problem into solvable pieces, four projects were formed to respectively address each of the following science questions: (1) How do atmospheric waves connect tropospheric weather with ionosphere/thermosphere variability? (2) What is the relation between atmospheric waves and ionospheric instabilities? (3) How do the different types of waves interact as they propagate through the stratosphere to the ionosphere? (4) How do thermospheric disturbances generated by auroral processes interact with the neutral and ionized atmosphere?
Several observational campaigns were conducted within each project, supported by regular workshops, conference sessions, and business meetings. Results were not only disseminated through the peer-reviewed literature but also to the broader CAWSES community through quarterly TG4 newsletters. This paper describes these activities and reviews the progress made over the CAWSES-II period from 2009 to 2013. Each project and its scientific outcomes are described in a separate section. The manuscript concludes with a general discussion of the outcomes, the scientific challenges for the future, new satellite missions, and SCOSTEP's new VarSITI program. More results related to TG4 can be found in the four special issues listed in Table 2 and in a special issue of Earth, Planets and Space dedicated to results presented at the International CAWSES-II Symposium (2014) held at Nagoya University, Japan, 18 to 22 November 2013.

\section{Review}

\section{Project 1: How do atmospheric waves connect} tropospheric weather with ionosphere/thermosphere variability?

The impact of atmospheric waves on ionospheric structure and variability has been realized for quite some time. Hines (1960) in his pioneering work was the first to propose GW as the cause of 'irregular motions' in the thermosphere and ionosphere. Since then, numerous studies have revealed that GWs are present at heights up to the upper thermosphere and connected them to medium-scale traveling ionospheric disturbances (MSTIDs), ionospheric irregularities, and plasma instabilities. See for example the more recent review by Fritts and Lund (2011) and references therein. Before CAWSES-II, it was already known that GW from convection and jet streams in the lower atmosphere propagate into the mesosphere, dissipate their energy near the mesopause region, and/or penetrate into the thermosphere. However, despite some speculation about the initiation of various plasma instabilities by GW, the relation between GW and MSTID, day-to-day variability and zonal separation of plasma bubbles, and the scale size and propagation of sporadic-E patches were not understood. The examination of the relationship between these phenomena and an improved understanding of the importance of GW in ionosphere/thermosphere dynamics were objectives for CAWSES-II.

The idea that global winds in the ionosphere may be a source of disturbance electric fields and currents goes

Table 1 Basic characteristics of atmospheric waves

\begin{tabular}{llll}
\hline & Gravity (buoyancy) waves & Atmospheric tides & Planetary waves \\
\hline Spatial scale & Local; 10 to 1,000 s of kilometers & Global; 10,000 s of kilometers & Global; 10,000 s of kilometers \\
Temporal scale & Minutes to hours & 1 day or harmonics & Days to weeks \\
Excitation & Mechanical distortions, latent heating & Solar heating, latent heating & Mechanical distortions, baroclinic instabilities \\
\hline
\end{tabular}


Table 2 Special issues with significant TG4 contributions

\begin{tabular}{|c|c|c|c|}
\hline Title & Journal & Year & TG4 relation \\
\hline Coupling between the lower and upper atmosphere & JGR Space Physics & 2010 & General topic \\
\hline $\begin{array}{l}\text { Coupling between the Earth's atmosphere and its } \\
\text { plasma environment }\end{array}$ & $\begin{array}{l}\text { Space Science Review, Vol. 168, } \\
\text { Issue 1-4, } 2012\end{array}$ & 2012 & ISSI workshop, see TG4 newsletter vol. 3 \\
\hline $\begin{array}{l}\text { Recent progress in the vertical coupling in the } \\
\text { atmosphere-ionosphere system }\end{array}$ & $\begin{array}{l}\text { J. Atmos. Sol. Terr. Phys., Vol. 90-91, } \\
\text { pages 1-222, December } 2012\end{array}$ & 2012 & $\begin{array}{c}\text { 4th IAGA/ICMA/CAWSES-II TG4 workshop } \\
\text { on vertical coupling }\end{array}$ \\
\hline $\begin{array}{l}\text { Recent advances in equatorial, low-, and mid-latitude } \\
\text { aeronomy }\end{array}$ & $\begin{array}{l}\text { J. Atmos. Sol. Terr. Phys., Vol. 103, } \\
\text { pages 1-194, October } 2013\end{array}$ & 2013 & ISEA-13 conference \\
\hline
\end{tabular}

back at least to the dynamo theory by Stewart (1882); the connection to Sun-synchronous (migrating) atmospheric tides forced by solar radiation absorption was discussed by Fejer (1964). As tidal theory and observational diagnostics progressed, it was realized that non Sunsynchronous (nonmigrating) tides forced by deep tropical convection are equally important for explaining longitudinal and local time variations in bulk neutral and plasma properties of the ionosphere/thermosphere system. Satellite diagnostics (Forbes et al. 2006; Oberheide et al. 2006b; Sagawa et al. 2005; Immel et al. 2006) and models (Hagan and Forbes 2002; Hagan et al. 2007) resulted in a basic quantitative knowledge of tidal forcing, propagation, and morphology in the mesosphere and lower thermosphere, the ionosphere, and a basic qualitative knowledge about the coupling into the F-region through E-region dynamo modulation. It should be noted that important contributions came from CAWSES-I activities, for example, from the CAWSES tidal campaigns (Ward et al. 2010) that effectively resolved the long-standing issue between groundbased radar and satellite optical measurements of winds. See also Kishore Kumar et al. (2013) for a recent comparison between radar, satellite, and model results obtained during the first CAWSES tidal campaign in 2005. Major challenges for CAWSES-II included the elucidation of tidal structures in the altitude range between 110 (upper altitude observed by TIMED) and $400 \mathrm{~km}$ (in situ tidal diagnostics from CHAMP) where suitable satellite observations are lacking, temporal variations of the tides on timescales ranging from days to solar cycle, a better separation of E-region dynamo modulation vs tidal coupling at F-region heights, an assessment of the tidal impacts on the energy balance and composition of the thermosphere, and wave-wave and wave-mean flow interactions. Similar questions are applied to PW as well, with special interest in their role in connecting polar stratospheric warmings with F-region low latitude plasma density variability (Goncharenko and Zhang 2008), as further detailed in project 3 .

\section{Gravity waves}

Gravity waves generated by convective systems, hurricanes, and surface perturbations such as earthquakes and tsunamis may seed plasma bubbles in the ionosphere through Rayleigh-Taylor instability. Figure 1 shows GW in airglow images at $630 \mathrm{~nm}$ (approximately $250 \mathrm{~km}$ ) caused by the tsunami from the catastrophic Tohoku earthquake on 11 March 2011 when it passed the Hawaiian Islands. See Makela et al. (2011) for details and also for a movie that includes the ionospheric response in total electron
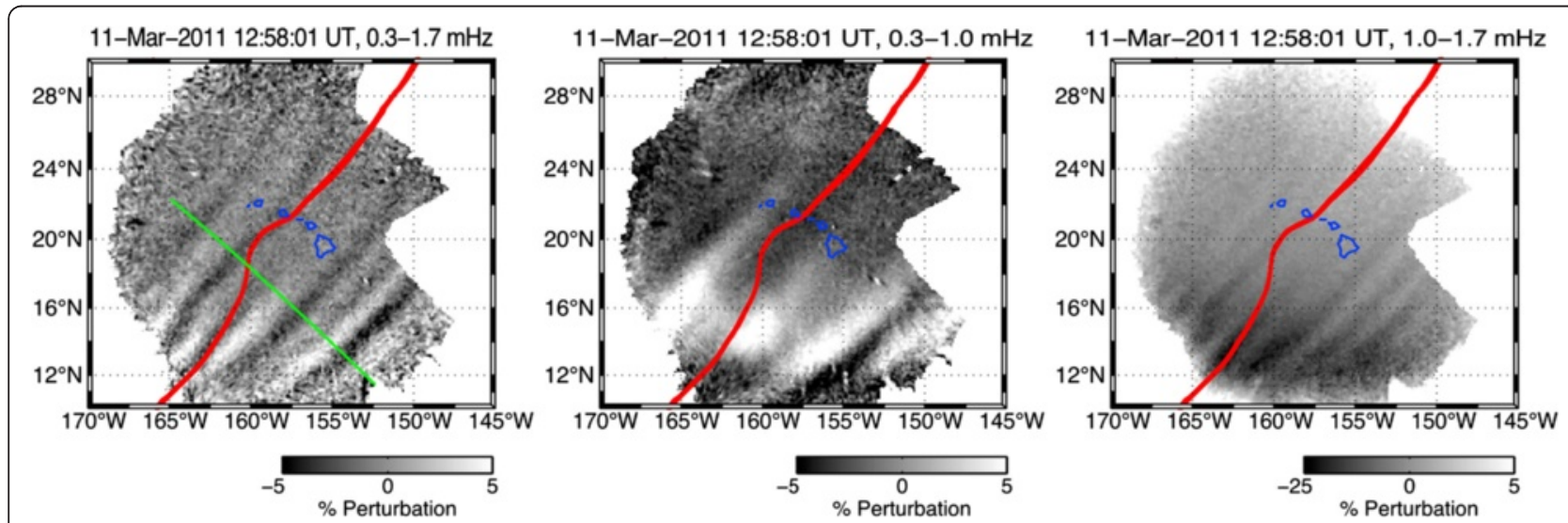

Figure $1 \mathrm{GW}$ in airglow images at $\mathbf{6 3 0} \mathrm{nm}$ caused by the tsunami from the Tohoku earthquake. Example of $630.0 \mathrm{~nm}$ images processed using length-8 FIR filters with passbands of (left) 0.3 to $1.7 \mathrm{mHz}$, (middle) 0.3 to $1.0 \mathrm{mHz}$ to highlight the 26.2-min period waves, and (right) 1.0 to $1.7 \mathrm{mHz}$ to highlight the 14.2-min period waves. The red line in each image indicates the tsunami location at the time of the image. The green line in the left panel indicates a path perpendicular to the airglow wave fronts. Adapted with permission from Makela et al. (2011). See also the movie in the electronic supplement to Makela et al. (2011). 
content (TEC). The ionospheric response over Japan (Figure 2) for the same event shows very pronounced concentric waves in TEC that propagate in the radial direction with a velocity between 138 and $3,457 \mathrm{~m} / \mathrm{s}$ with an 'ionospheric epicenter' about $170 \mathrm{~km}$ southeast from the earthquake epicenter (Tsugawa et al. 2011). The initial signatures in Figure 2 with a propagation velocity of 3,457 m/s are most likely caused by a Rayleigh wave (a type of surface wave during earthquakes), followed by acoustic waves triggered by the Rayleigh wave. Finally, medium-scale concentric waves with a propagation velocity of 138 to $423 \mathrm{~m} / \mathrm{s}$ were detected $300 \mathrm{~km}$ away from the ionospheric epicenter (Figure $2 \mathrm{~g}, \mathrm{~h}$ ). They are the result of GW forced by the surface displacement (Matsumura et al. 2011).

Nishioka et al. (2013) discussed similar concentric waves in the ionospheric TEC variation over the North-American continent as an indicator of thermospheric gravity waves generated by the 2013 Moore EF5 tornado. Fukushima et al. (2012) showed correlation of MSTIDs observed by a $630 \mathrm{~nm}$ airglow imager over Indonesia with tropospheric convective activity but with the average horizontal wavelength of the MSTIDs increasing with decreasing solar activity. These findings suggest that the observed MSTIDs in the equator are caused by secondary gravity waves in the thermosphere, possibly generated by tropospheric convective activity. Smith et al. (2013) reported on thermospheric secondary GWs generated from mountain wave breaking in the upper mesosphere using a simultaneous observation of $630 \mathrm{~nm}$ and $557.7 \mathrm{~nm}$ airglow images over New Zealand.

Progress in gravity wave theory (e.g., Vadas and Liu 2009; Vadas and Crowley 2010; Yiğit et al. 2012; Gavrilov and Kshetvetskii 2014) now provides a much clearer picture of how gravity waves from the lower atmosphere can reach thermospheric altitudes, involving a multitude of possible pathways including direct propagation, reflection in the upper atmosphere, and the generation of secondary waves through upper mesospheric and thermospheric body forces (Figure 3). As a result, substantial neutral horizontal wind and plasma density variations from a single convective plume are predicted to occur as far away as adjacent continents, pointing to local wave sources having a global impact: a significant challenge for the interpretation of observations. An example of the ionospheric response to convective activity over Brazil on 1 October 2005 is shown in Figure 4 which is adapted from Vadas and Liu (2013). Thermospheric body forces resulting from convective plumes are computed with the Vadas model. Their incorporation into the Thermosphere-Ionosphere-Mesosphere-Electrodynamics General Circulation Model (TIME-GCM) results in largescale traveling ionospheric disturbances. Of note is that the $h_{m} F 2$ ' perturbations are generally anticorrelated with the $\mathrm{f}_{\mathrm{o}} \mathrm{F} 2^{\prime}$ and $\mathrm{TEC}$ ' perturbations. This indicates that field-aligned transport instead of chemistry (i.e., [e ] + $\left[\mathrm{O}^{+}\right]$recombination) may be the dominant coupling

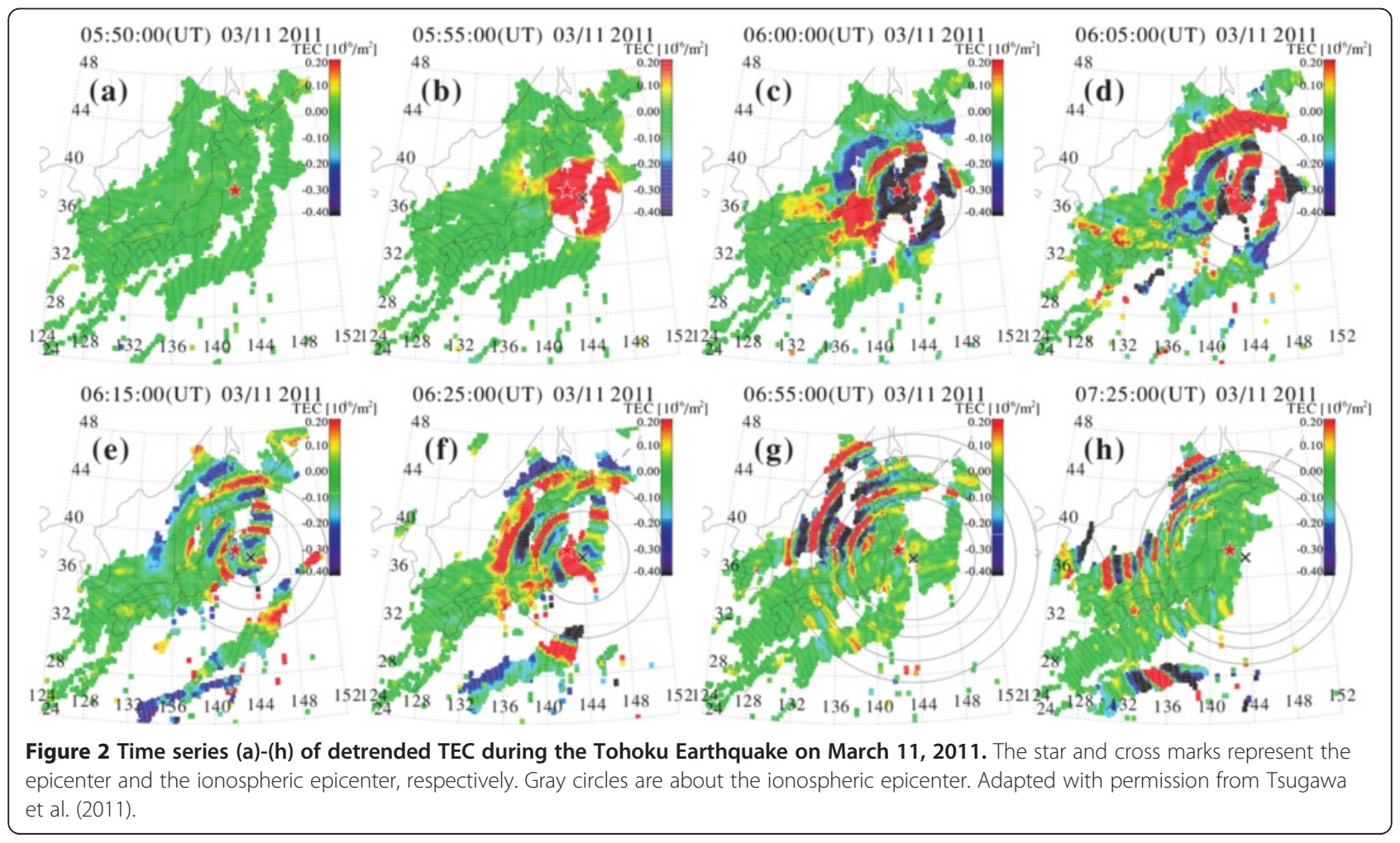




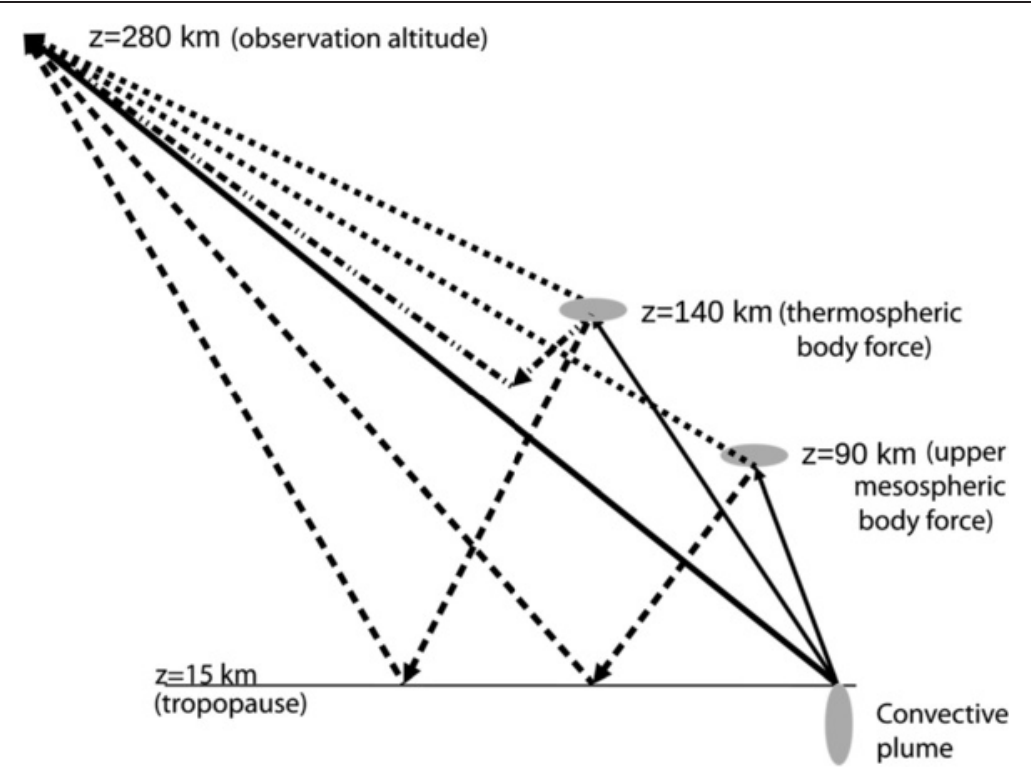

Figure 3 Sketch of possible pathways of a GW. Sketch of possible pathways of a GW from a single convective plume including direct propagation (solid line), creation of body forces (grey ellipses), and subsequent generation of secondary GW with possible reflection (dotted and dashed-dotted lines). Adapted with permission from Vadas and Crowley (2010).

mechanism into the plasma. Observing such signatures still poses a significant challenge. Corresponding temperature perturbations in the thermosphere (not shown) will be observed from geostationary orbit in the near future by the Global-scale Observations of the Limb and Disk (GOLD) instrument (a UV imager to be launched in 2017; Eastes et al. 2008). For the ionospheric signatures, much progress can be expected from Swarm, an ESA constellation mission (Haagmans et al. 2013) that was launched in 2013. The role of GW for ionospheric instability seeding was the focus of TG4 project 2 and is further discussed in the corresponding section later in this paper.

\section{Tides}

The components of the tidal spectrum that follow the apparent westward propagation of the Sun relative to the Earth's surface are called migrating tides, and the non-Sun-synchronous components are called nonmigrating tides. Migrating tides are predominantly forced by solar radiation absorption in tropospheric water vapor and stratospheric ozone. Nonmigrating tides are thought to have two major sources: non-linear wave-wave interaction processes in the strato-/mesosphere (Hagan and Roble 2001) and latent heating due to large-scale deep convection in the tropical troposphere (Hagan and Forbes 2002, 2003). Deep convection largely depends on land-sea differences and sea-surface temperatures. Variations in the periodic absorption of solar radiation at the surface thus transform to a longitudinal structure in raindrop formation (heat release) at roughly the same local time of the day that acts as an efficient forcing mechanism for a number of nonmigrating tides including the diurnal eastward propagating tide of zonal wavenumber 3 (DE3). Note that the DE3 appears as a zonal wavenumber 4 (wave-4) longitudinal structure when observed at constant local solar time, e.g., by precessing satellites in a low Earth orbit. This is simply a result of its eastward propagation and frequency.

Figure 5 summarizes the pre-CAWSES-II knowledge of the cause-and-effect chain between latent heat forcing, tidal propagation, and coupling into the ionosphere, based on various satellite observations. The most striking pattern is a 4-peaked 'wave-4' longitudinal modulation that is apparent in deep convective cloud occurrence, E-region zonal winds, thermospheric constituents, F-region electron and ion density, and upper thermosphere neutral mass density. Nonmigrating tidal winds in the low and middle latitude E-region move the partially ionized plasma through Earth's magnetic field while the electrons with their high gyro frequency/collision frequency ratio remain fixed to the magnetic field lines. An electromotive force is thus created with ensuing electric currents and polarization electric fields. The E-region dynamo polarization fields are further transmitted along magnetic field lines into the overlying F-region where they drive vertical (approximately $20 \mathrm{~m} / \mathrm{s}$ ) and horizontal (approximately $100 \mathrm{~m} / \mathrm{s}$ ) plasma drifts, which influence many important ionospheric processes. For example, vertical ExB drifts drive the plasma fountain, which results in dense bands of plasma centered near \pm 15 to 20 magnetic latitude. This equatorial ionization anomaly can be seen in the top center panel of Figure 5 as the two bluish bands north and south of the equator. The 


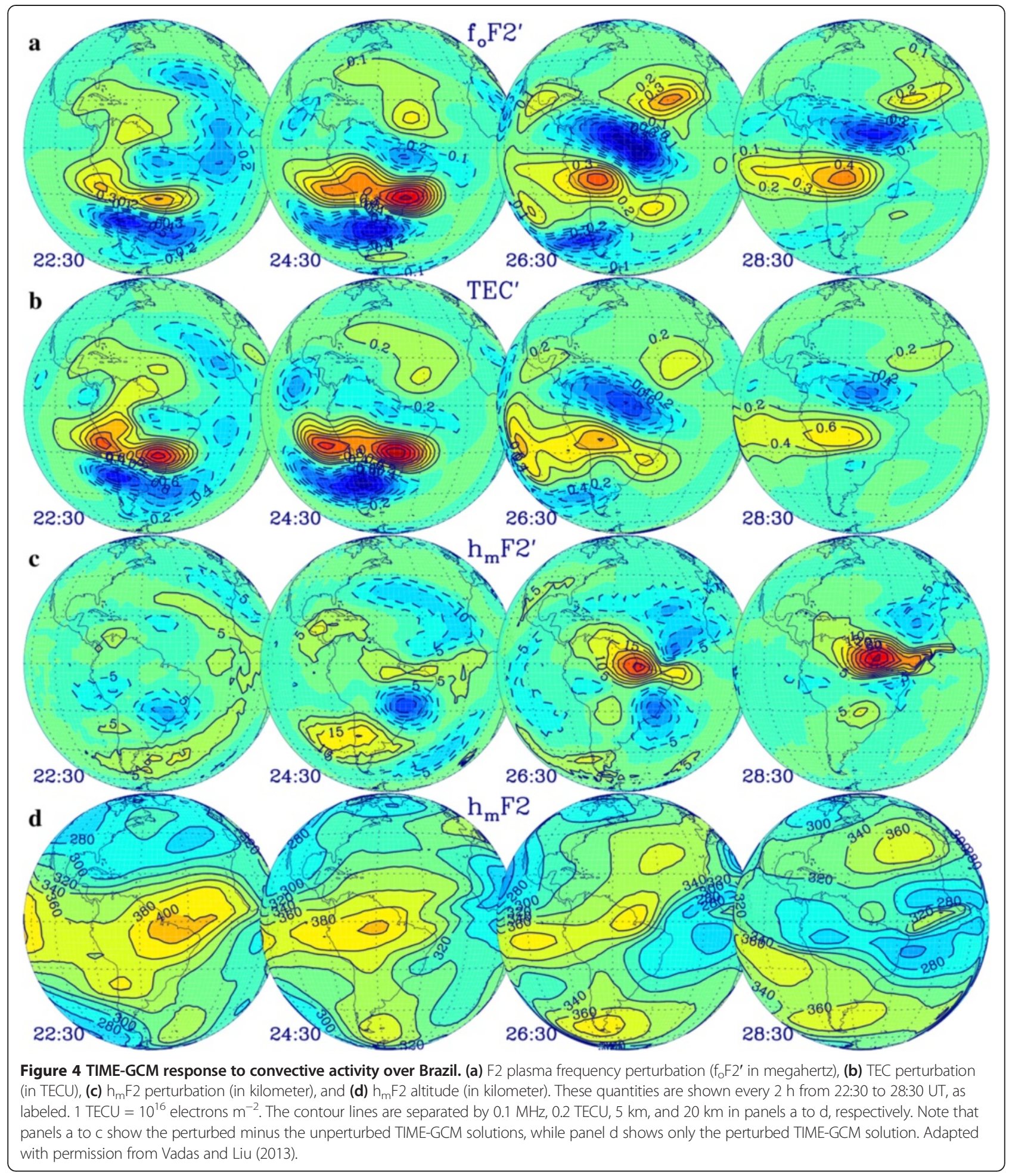

occurrence of the two ionization crests is predominantly the result of migrating solar tidal winds in the E-region, while the apparent longitudinal modulation in these bands is the result of nonmigrating tides excited by latent heat release in the tropical troposphere. For example, electron density varies by a factor of 2 to 3 as a function of longitude along the crests of the equatorial ionization anomaly at \pm 15 magnetic latitude (top left panel in Figure 5) and reflects the largescale convective activity in the low-latitude troposphere. This surprising discovery that global conditions in the ionosphere and thermosphere are linked strongly to the terrestrial weather and climate below was initiated by IMAGE satellite 


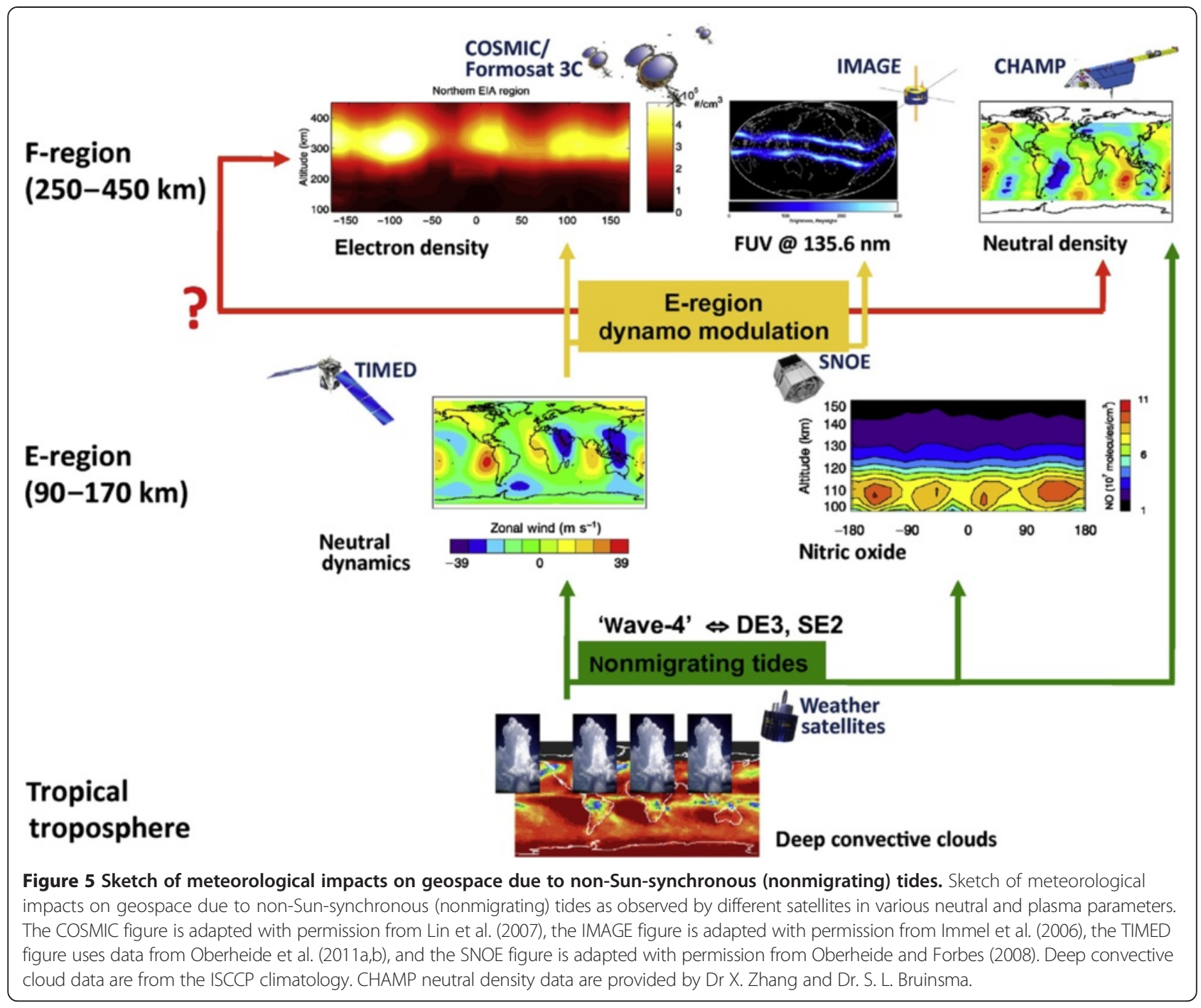

observations of the F-region plasma density (Sagawa et al. 2005; Immel et al. 2006).

This general picture has been confirmed during the CAWSES-II period by coupled ionosphere/thermosphere models (e.g., Jin et al. 2011; Maute et al. 2012) and studies using satellites, e.g., in temperature (Forbes et al. 2009), infrared cooling (Oberheide et al. 2013), and plasma density (Chang et al. 2013). However, it has now been realized that alternative effects, in addition to the E-region dynamo modulation, may contribute to the coupling between the tides and the ionospheric plasma: for instance neutral density variations, changes in thermospheric atomic oxygen to nitrogen ratio, and meridional winds at F-region altitudes (Liu et al. 2009; England et al. 2010; Maute et al. 2012; see also the review article by England (2012)).

It should also be noted that tidal wind shears in the E-region play a significant role in forming ionospheric intermediate layers, called sporadic E. See for example the early work by Fujitaka and Tohmatsu (1973) and the review by Haldoupis (2011). Much progress in this field, particularly in investigating the spatio-temporal distribution of occurrence frequency, has been made during the CAWSES-II period. Important contributions came from the concurrent analysis of COSMIC radio occultation and TIMED tidal diagnostics. For example, it has now been realized that, in addition to the diurnal and semidiurnal tides, the terdiurnal migrating tide plays an appreciable role in the sporadic E formation (Fytterer et al. 2014). There is also growing evidence for an important role of nonmigrating tides on the sporadic E formation but this topic needs to be studied further in the future.

Some progress was also made in elucidating day-to-day tidal variability. Forbes et al. (2011) combined CHAMP and GRACE exosphere temperatures to perform daily tidal fits for selected time periods and found mainly solar-driven variability with a strong correlation with 
the 27-day solar rotation period (Figure 6). Using combined WACCM-X/TIME-GCM simulations with constant solar and geomagnetic conditions but realistic tropospheric weather patterns, Liu et al. (2013a,b) showed day-to-day tidal amplitude variability on the order of $50 \%$ for the DW1, DE2, and DE3 tidal components in thermospheric winds, respectively. This in turn produced ExB vertical drift variability of the same magnitude and clearly indicates that tropospheric weather variability imposes a significant day-to-day variability on the ionosphere. At lower altitudes (mesosphere), Nguyen and Palo (2013) combined sounding the atmosphere using broadband emission radiometry (SABER) and microwave limb sounder (MLS) temperature data to derive day-to-day migrating diurnal tide variability at low latitudes and found amplitude changes of up to $15 \mathrm{~K}$ from one day to another. This is of the same order as variability deduced from 'deconvolution' approaches (Oberheide et al. 2002) using SABER alone (Figure 7). The causes for this variability still need to be understood. It is not yet clear what the relative roles of tropospheric source variability and modulations imposed by wave-wave and wave-mean flow interaction processes are in causing this variability. Addressing this challenge is not only a matter of diagnosing short-term tidal variability from the data but will also require a concentrated effort by the modeling community. For example, a comparison of the diurnal tide in models and ground-based observations conducted as part of the 2005 equinox CAWSES tidal campaign (Ward et al. 2010) points to considerable differences in model magnitudes and vertical wavelengths suggesting that inconsistencies in model forcing, dissipation, and background winds exist (Chang et al. 2012).

On longer time-scales, it has become clear that changes in global-scale weather patterns impose a considerable variability in the thermosphere and ionosphere. A compelling example that has recently attracted attention is the effect of the El Niño Southern Oscillation (ENSO). Pedatella and Forbes (2009a) found a high correlation between the

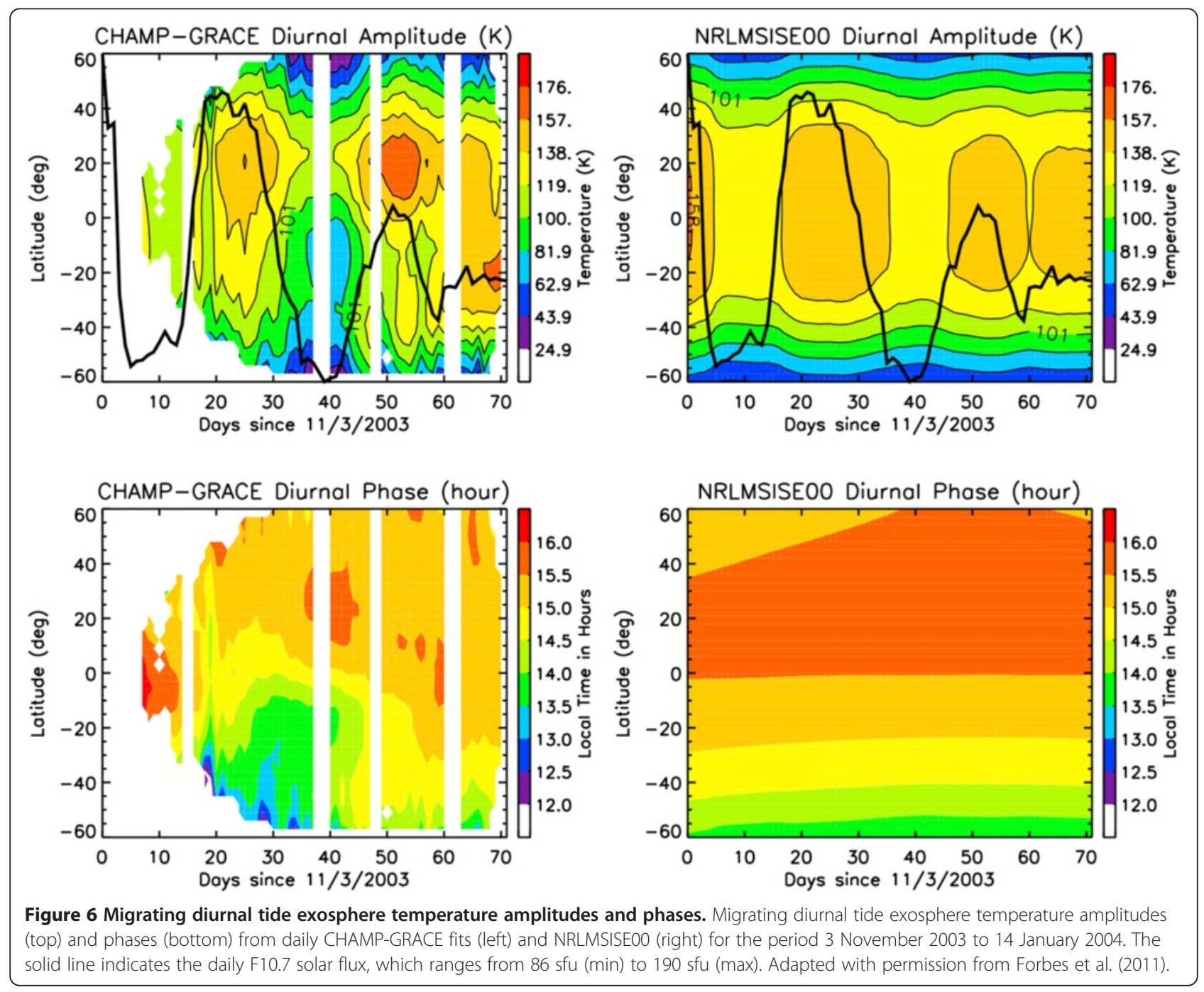




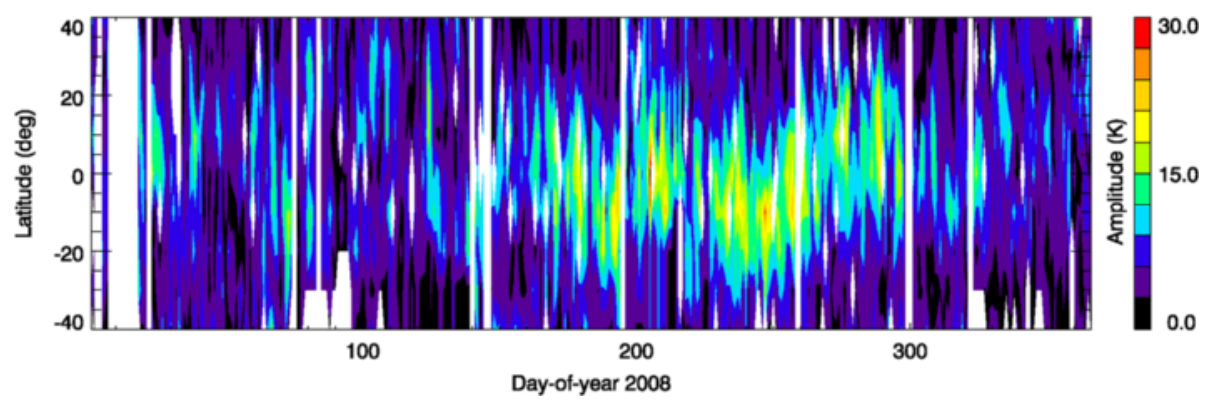

Figure 7 Day-to-day DE3 tidal amplitude variability in $\mathbf{2 0 0 8}$ at $\mathbf{1 0 0} \mathbf{~ k m}$ from SABER. Day-to-day DE3 tidal amplitude variability in 2008 at $100 \mathrm{~km}$ from SABER using a 'deconvolution' approach, plotted as a function of day of year and latitude. White color indicates data gaps.

Oceanic Niño Index $(\mathrm{ONI})$ and longitudinal $\mathrm{f}_{\mathrm{o}} \mathrm{F}_{2}$ variability from low latitude ionosondes and associated this with ENSO-related changes in DE3 convective tidal heating. In a follow-up modeling study using WACCM, Pedatella and Liu (2012) showed that ENSO imposes a tidal temperature variability on the order of $10 \%$ to $30 \%$ during northern hemisphere winter. Interestingly, they found an enhanced DW1 and SW4 during the El Niño phase but a reduced DE2 and DE3. The latter components are enhanced during the La Niña phase. This is consistent with recent TIMED Doppler interferometer (TIDI) diagnostics focused on ENSO variability (Warner and Oberheide 2014). The ENSO-imposed variability is generally smaller than the short-term tidal variability but similar to variability due to the quasi-biannual oscillation $(\mathrm{QBO})$ determined by Oberheide et al. (2009). The ionospheric response to ENSO still needs to be studied in detail. A preliminary analysis (Figure 8) based on the COSMIC-based TEC tides from Chang et al. (2013) and the TIDI-, Tropical Rainfall Measuring Mission (TRMM)-, and Modern-Era
Retrospective Analysis for Research and Applications (MERRA)-based tidal wind and heating diagnostics from Warner and Oberheide (2014) indicates a consistent 50\% enhancement in DE3 during the La Niña phase of the strong 2009 to $2011 \mathrm{ENSO}$ and no response during the El Niño phase.

Tropospheric tidal forcing does not respond appreciatively to the solar cycle, and the E-region dynamo tidal winds remain more or less unaffected (Oberheide et al. 2009). In the thermosphere above $120 \mathrm{~km}$, however, increasing background temperatures during higher solar activity cause more tidal dissipation because of the temperature dependence of thermal conductivity. For example, DE3 amplitudes during solar minimum are much larger than during solar maximum: a factor of 3 in the zonal wind, $60 \%$ in temperature and a factor of 5 in density (Oberheide et al. 2009; Häusler et al. 2013). On the other hand, relative TEC tidal amplitudes from COSMIC (Chang et al. 2013) do not show any solar cycle dependence. This can be understood as the result

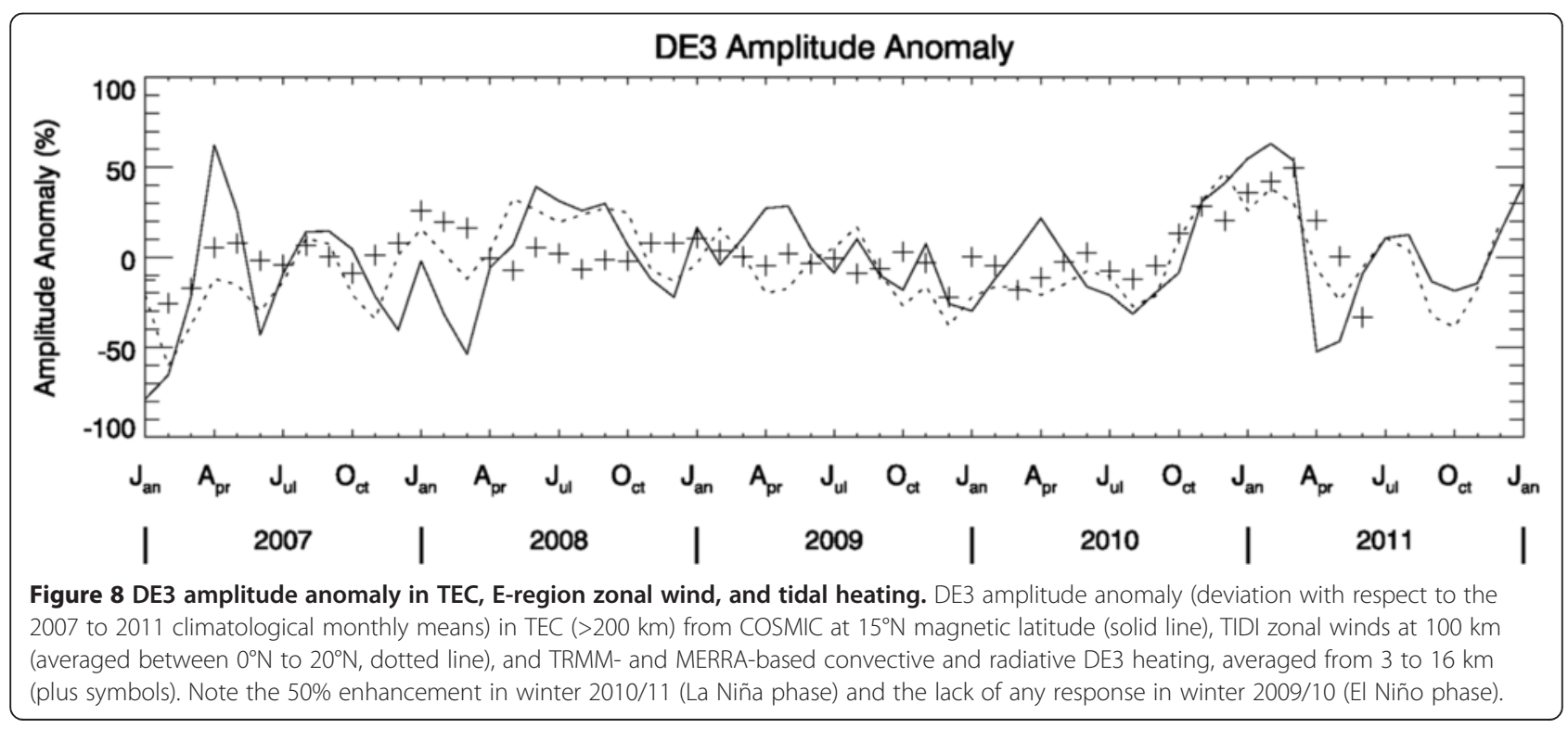


of the absence of any solar cycle dependence in the zonal wind tides in the dynamo region which are the main driver of ionospheric tidal variability.

Connecting tides observed in the mesosphere lower thermosphere (MLT) region and those in the upper thermosphere and thus making the full connection to tropospheric weather from a purely observational point is still hampered by the lack of global wind or temperature observations in the 'thermospheric gap' between TIMED observations (reliable below $110 \mathrm{~km}$ ) and in situ observations from satellites like CHAMP, GRACE, or the new Swarm mission at altitudes generally above $200 \mathrm{~km}$. For example, much of the tidal characteristics in this height region rely on fits to TIMED observations such as the Climatological Tidal Model of the Thermosphere (CTMT, Oberheide et al. 2011a) that uses the observed tides in the MLT region as a constraint for a physics-based empirical model or general circulation models like WACCM-X (Liu et al. 2010a). The only dataset to date that turned out to be suitable for thermospheric tidal diagnostics came from HRDI and WINDII on UARS observations with tidal 'deconvolution' applied (Lieberman et al. 2013a). Figure 9 exemplifies this for the DE3 using HRDI/WINDII diagnostics from 60 to $250 \mathrm{~km}$ compared to CTMT. While CTMT does a reasonable prediction in this example, other components are not well reproduced, particularly DW2 and D0 that have additional in situ thermospheric sources, as shown by Jones et al. (2013) using the TIME-GCM. The existence of in situ thermospheric tidal sources for DW2 and D0 was confirmed by Forbes et al. (2014) who used the CTMT and combined CHAMP/GRACE tidal diagnostics to study tidal penetration to the upper thermosphere.

In continuation of the CAWSES-I tidal campaigns (Ward et al. 2010), TG4 continued the data analysis (e.g., Chang et al. 2012; Kishore Kumar et al. 2013) and conducted an additional campaign in August to October 2011. These campaign data still need to be analyzed and results will be published elsewhere. Although requiring a significant international effort, observational campaigns such as these for various tropospheric and stratospheric conditions (ENSO, QBO) are important for developing and confirming our understanding of tidal variability. See for example the recent modeling results by Gan et al. (2014) that highlight interannual variability in satellite-borne tidal diagnostics and in a general circulation model nudged to observed meteorological reanalysis data. It should also be noted that tides provide the link between the 'weather' of the polar stratosphere and ionospheric variability close to the geomagnetic equator, e.g., during sudden stratospheric warmings (SSW) as a result of planetary wave - tidal interaction. This is further elaborated on in project 3 .
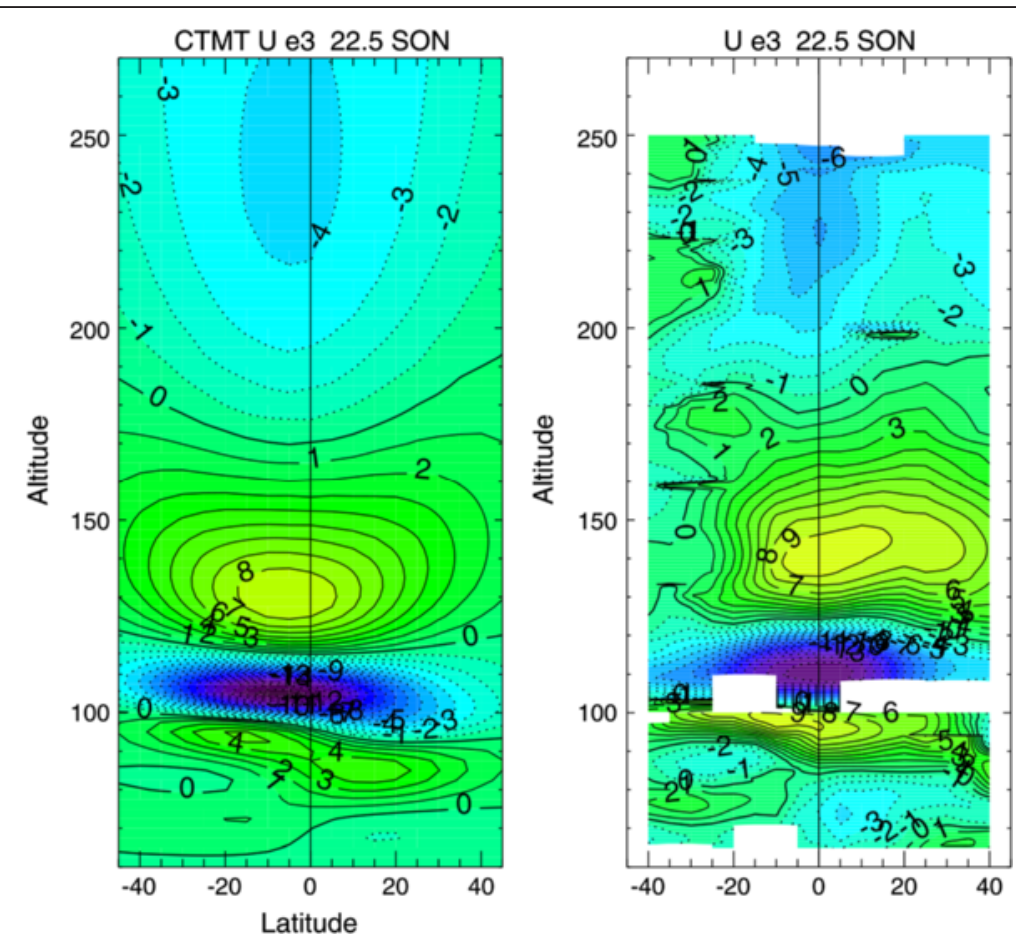

Figure 9 DE3 amplitudes from CTMT and WINDII. (Left) DE3 amplitudes ( $\mathrm{m} / \mathrm{s}$ ) computed from CTMT averaged over September to November and mapped to $17: 00$ to $07: 00$ local time difference at $22.5^{\circ}$ E. (Right) Same as left but from HRDI and WINDII analysis. White areas are data gaps. Adapted with permission from Lieberman et al. (2013). 


\section{Project 2: What is the relation between atmospheric waves and ionospheric instabilities?}

Equatorial plasma instabilities, commonly referred to as equatorial spread-F, plasma bubbles, or depletions can cause radio signals propagating through the disturbed region to scintillate resulting in a distortion or loss of signal. First observed by Booker and Wells (1938), they have been extensively studied due to the increasing importance of satellite-based communications and positioning. Much has been learned over the decades about the growth mechanism and occurrence variability on a seasonal timescale. Dungey (1956) suggested the RayleighTaylor instability as the generating process during postsunset at the magnetic equator. At this time and location, since the bottom side of the $\mathrm{F}$ layer has recombined while the entire $\mathrm{F}$ layer itself has been raised by the pre-reversal enhancement, a very sharp vertical density gradient is created that is unstable to vertical perturbations in the ionosphere. Identifying the contribution of atmospheric waves as a perturbation source and studying the resulting instabilities was the leading motivation for two observational campaigns carried out as part of TG4 activities.

\section{The SpreadFEx-2 campaign}

Based on the success of the first SpreadFEx campaign held in northeastern Brazil (e.g., Fritts et al. 2008), which focused on studying the interaction between the neutral atmosphere and ionosphere, especially during periods of ionospheric irregularities, a second set of campaigns, called SpreadFEx-2, was carried out in 2009 and 2010. A total of eight institutions participated in these campaigns, deploying instruments to the sites detailed in Table 3. The addition of the coherent electromagnetic radio tomography (CERTO) beacon receivers and deployment of multiple wide-angle imaging systems added the possibility of performing tomographic inversions of the ionosphere during periods of ionospheric irregularities while the deployment of Fabry-Pérot interferometers (FPIs) added the capability to directly measure neutral winds and temperatures and study the relationship between the neutral and plasma state.

The campaigns were operated from early September until the end of November in both 2009 and 2010. These months correspond to the beginning of the 'spread- $F$ ' season, so called since this is when the occurrence of ionospheric irregularities (known as spread-F or equatorial plasma bubbles) is more common. Combining data from the imaging systems and FPIs, the coupling of the neutrals and plasma during periods of equatorial plasma bubbles (EPBs) was studied. Chapagain et al. (2012) found that the zonal neutral winds and EPB zonal drift velocity, which is assumed to be indicative of the background plasma drift velocity, were tightly correlated, especially beginning several hours after sunset. The zonal velocities showed similar patterns of both nightly and night-to-night variability, indicating that the F-region dynamo was fully developed. Earlier in the evening, however, the EPB zonal speed was found to be slower than the background neutral winds, indicating that during the period of bubble development, the F-region dynamo might not be fully activated. Examples of the comparisons made during the SpreadFEx-2 2009 campaign are shown in Figure 10. These examples show the overall similarity between the winds and EPB drift velocities as well as the variability in both of these parameters on a night-to-night basis. Histograms showing the difference between the measured winds and estimated EPB drift velocities are shown in Figure 11 and show the good agreement between the two zonal speeds seen later in the evening (after $23 \mathrm{LT}$ ).

The data collection that begun under the SpreadFEx-2 campaigns has been continued through 2013, allowing for the study of the low latitude thermosphere through the transition from the deep solar minimum toward the solar maximum of solar cycle 24. A summary of the zonal and meridional thermospheric neutral winds as

Table 3 Spread FEx2 observation sites

\begin{tabular}{|c|c|c|c|c|c|c|c|c|c|c|}
\hline & $\begin{array}{c}\text { (Latitude } \\
\text { longitude) }\end{array}$ & Ionosonde & Imager & FPI & Photometer & $\begin{array}{l}\text { Meteor } \\
\text { radar }\end{array}$ & $\begin{array}{l}\text { VHF } \\
\text { radar }\end{array}$ & $\begin{array}{l}\text { CERTO } \\
\text { receiver }\end{array}$ & $\begin{array}{l}\text { GPS } \\
\text { receiver }\end{array}$ & $\begin{array}{l}3 \text { point } \\
\text { sounding }\end{array}$ \\
\hline São Luís & $\left(2.6^{\circ} \mathrm{S}, 44.2^{\circ} \mathrm{W}\right)$ & DPS4 & & & & & OK & & OK & \\
\hline Fortaleza & $\left(3.9^{\circ} \mathrm{S}, 38.4^{\circ} \mathrm{W}\right)$ & DPS4 & & & & & & & & \\
\hline Cariri & $\left(7.4^{\circ} \mathrm{S}, 36.5^{\circ} \mathrm{W}\right)$ & CADI & All sky 6300, OH & 6300 & OH temperature & OK & & & & $\begin{array}{c}\text { Transmission } \\
\text { receiver }\end{array}$ \\
\hline Cajazeiras & & & 6300 & 6300 & & & & OK & OK & \\
\hline Petrolina & & & All sky 6300, OH & & & & & OK & & \\
\hline Caico & & & & & & & & & & Transmission \\
\hline $\begin{array}{l}\text { Campina } \\
\text { Grande }\end{array}$ & & & & & & & & OK & & Transmission. \\
\hline C. Paulista & $\left(22.7^{\circ} \mathrm{S}, 45.0^{\circ} \mathrm{W}\right)$ & DPS4 & All sky 6300, OH & & Multichannel & & & & OK & \\
\hline Institution & & INPE & INPE, USU, UI & UI and Clemson & UFCG & INPE & INPE & $N R L$ & UI, INPE & UWO, INPE \\
\hline
\end{tabular}



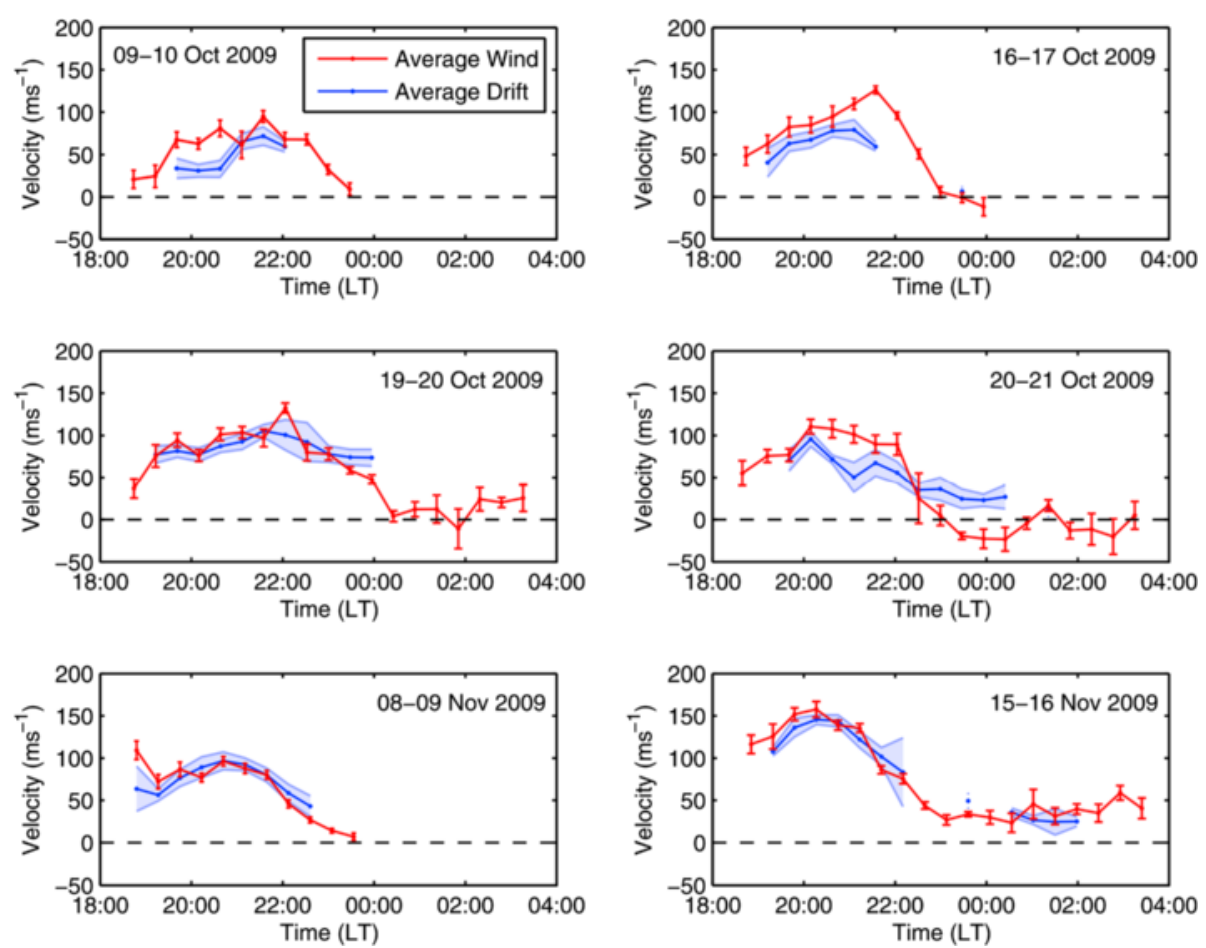

Figure 10 Comparisons of thermospheric neutral winds and equatorial plasma bubble drift velocities. Comparisons of thermospheric neutral winds (red) and equatorial plasma bubble drift velocities (blue) collected during the SpreadFEx-2 campaign in 2009. Adapted with permission from Chapagain et al. (2012).

well as thermospheric neutral temperatures approximately $250 \mathrm{~km}$ through the end of 2013 are presented in Figure 12. Analysis of the data collected through the end of July 2012 by Makela et al. (2013) showed the expected strong dependence of the neutral temperature on the solar flux, with the average temperature increasing by several hundred Kelvin over the study period. However, a solar flux dependence was not seen in the neutral winds, at least over the range of solar fluxes observed during the period. Strong seasonal and day-to-day variability, however, is seen in the data indicating the influence of tidal and, possibly, gravity waves in the thermospheric neutral flows. The collection of this type of multi-year dataset will provide important validation to models of the thermosphere

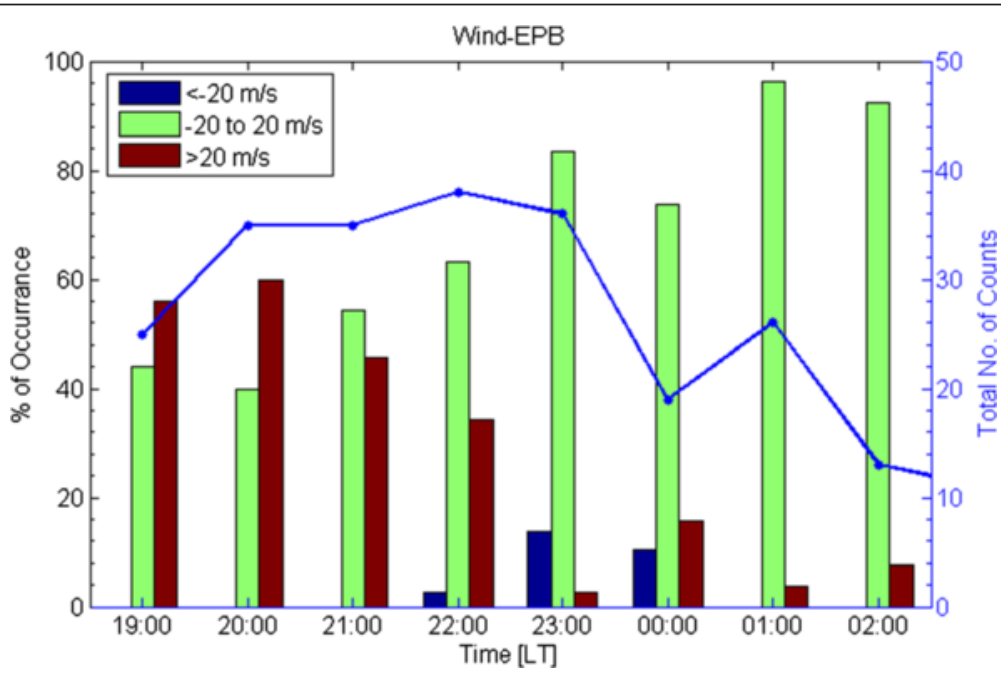

Figure 11 Histogram of differences between the thermospheric neutral wind and equatorial plasma bubble drift velocities. Binned by local time. Total number of coincident observations in each bin is indicated by the blue line, referenced to the right hand axis. 


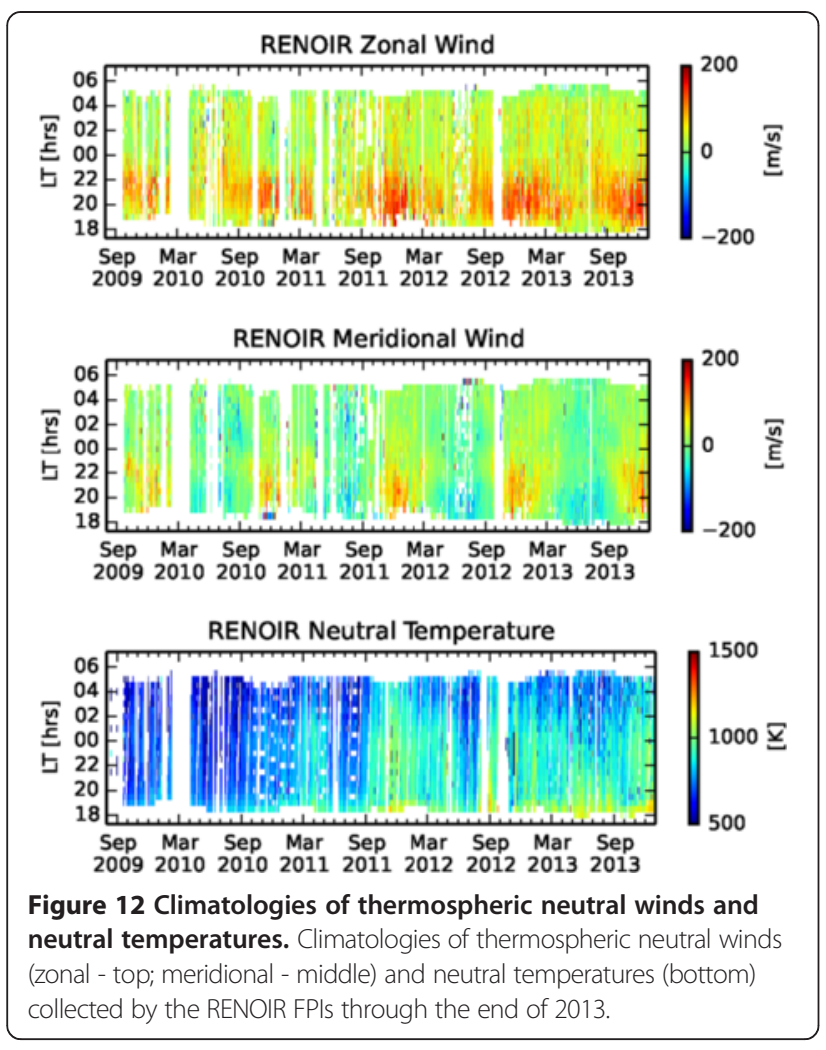

and ionosphere being developed. Such a validation study for the WAM using the dataset that begun under the CAWSES SpreadFEx-2 campaign is presented in Meriwether et al. (2013).

\section{The LONET campaign}

The LONgitudinal NETwork (LONET) campaign was carried out as a TG4 activity during the September to November period in 2010 and 2011 with the goal of creating a robust, global, multi-instrument database to study the longitudinal variability of planetary-scale waves. Table 3 lists the observation sites and instrumentation (13 ionosondes, 1 meteor radar, 2 MF radars, and 1 optical Fabry-Pérot interferometer) participating in LONET. TEC data obtained from the COSMIC satellite were also included. As can be seen from Table 4, the data collected in 2010 were more complete than 2011 in terms of the longitudinal coverage. Figure 13 shows the observation sites distributed along the equator marked on a map. The rectangular boxes depict COSMIC TEC data sampling along the magnetic equator. The ground-based data collection was limited in South America, Asia, and Oceania. No data were available from the African continent.

As the first step in understanding the longitudinal variability of waves, the LONET team studied whether any global-scale periodic oscillations were present in the observed parameters and how the amplitude of those oscillations varied with longitude. From the temporal variations of the ionospheric parameters foF2, h'F, TEC, and mesospheric winds, the 2- to 16-day oscillations were studied using wavelet analysis. In Figure 14, the wavelet power spectra for the three parameters, h'F at Fortaleza (FZA, $\left.321.6^{\circ} \mathrm{E}\right), \mathrm{TEC}$ at around $345^{\circ} \mathrm{E}$, and MF radar zonal wind component at Pameungpeuk $\left(107.7^{\circ} \mathrm{E}\right)$ are presented for the period consisting of day of year (DOY) 240 to 330. The h'F and TEC are approximately in the same longitudinal zone. Among the common oscillations seen in these parameters is a distinct 16-day period oscillation during DOY 260 to 300.

In order to further investigate the 16-day oscillation, the amplitude and phase of the oscillation observed in the h'F parameter observed by the network of ionosondes participating in the LONET campaign are plotted in Figure 15 for Fortaleza (FZA, top) to Darwin (DWN, second from the bottom). The mesospheric wind components (zonal winds at $89 \mathrm{~km}$ altitude), obtained from the MF radar at Pameungpeuk (PAM), are also shown (bottom) for reference. From the PAM wind oscillations in Figures 14 and 15, clear evidence of a 16-day oscillation during the period DOY 260 to 320 centered at around DOY 290 is found. The h'F at Fortaleza shows clear 16-day oscillations during the same period with an amplitude that reaches approximately $4 \mathrm{~km}$. However, the amplitudes of oscillation in the Indian and Asian sectors are somewhat lower compared to the American sites.

In Figure 16, we plot the results of a 16-day harmonic analysis of the COSMIC TEC data for different longitudinal zones. Each line corresponds to a given longitudinal zone, starting at $195^{\circ} \mathrm{E}$ (top) to $345^{\circ} \mathrm{E}$ (middle) to $165^{\circ} \mathrm{E}$ (bottom). During DOY 270 to 300 , the 16 -day oscillation feature can clearly be seen. The phase of the maximum is slightly shifted from DOY 290 at $15^{\circ} \mathrm{E}$ to DOY 300 at $195^{\circ} \mathrm{E}$, indicating that the phase is propagating westward. These observations suggest that the 16-day oscillations might be generated by the Rossby mode 16-day planetary wave (Forbes 1995). Furthermore, there appear to be low amplitude regions (195 to $255^{\circ} \mathrm{E}$ ) and high amplitude regions $\left(315\right.$ to $105^{\circ} \mathrm{E}$ ) in the global distribution of the oscillations. The Rossby 16-day waves normally appear in the troposphere to mesosphere mainly through the wind field and propagate into the lower thermosphere, modulating the ionosphere (Lastovicka 2006). The present results provide further understanding regarding the latitudinal and longitudinal variability of the 16-day waves.

In addition to the ionospheric data presented above, data on geomagnetic field variations were also collected during the campaign period. The results of comparison with the ionospheric parameters will be presented elsewhere. Longitudinal variability of the spread F activity was also investigated using ground-based TEC observation over South America. Large day-to-day variability of spread 
Table 4 LONET campaign observation sites

\begin{tabular}{|c|c|c|c|c|c|c|c|}
\hline Item & Site & Symbol & Latitude & Longitude & 2010 & 2011 & Contact \\
\hline \multicolumn{8}{|c|}{ lonosonde/foF2, h'F } \\
\hline 1 & Jicamarca & $\mathrm{JCM}$ & $12.0^{\circ} \mathrm{S}$ & $76.9^{\circ} \mathrm{W}$ & Partial & YES & Karim Kuyeng/Chau \\
\hline 2 & Fortaleza & FZA & $3.9^{\circ} \mathrm{S}$ & $38.4^{\circ} \mathrm{W}$ & YES & YES & Inez Batista \\
\hline 3 & C. Paulista & $\mathrm{CPT}$ & $22.7^{\circ} \mathrm{S}$ & $45.0^{\circ} \mathrm{W}$ & YES & YES & Inez Batista \\
\hline 4 & São Luís & SLS & $2.5^{\circ} \mathrm{S}$ & $44.3^{\circ} \mathrm{W}$ & YES & YES & Inez Batista \\
\hline 5 & Tirunelveli & $\mathrm{TIR}$ & $8.7^{\circ} \mathrm{N}$ & $77.8^{\circ} \mathrm{E}$ & YES & NO & Diwarker/Gurubaran \\
\hline 6 & Gadanki & GAD & $13.5^{\circ} \mathrm{N}$ & $79.2^{\circ} \mathrm{E}$ & YES & NO & A.K. Patra \\
\hline 7 & Cocos Islands & $\operatorname{COC}$ & $12.2^{\circ} \mathrm{S}$ & $96.8^{\circ} \mathrm{E}$ & YES & YES & Phil Wilkinson \\
\hline 8 & Chumphon & CPN & $10.7^{\circ} \mathrm{N}$ & $99.4^{\circ} \mathrm{E}$ & YES & NO & Nagatsuma \\
\hline 9 & Bac Lieu & $\mathrm{BCL}$ & $9.3^{\circ} \mathrm{N}$ & $105.7^{\circ} \mathrm{E}$ & YES & NO & Nagatsuma \\
\hline 10 & Sanya & SYA & $18.3^{\circ} \mathrm{N}$ & $109.6^{\circ} \mathrm{E}$ & YES & YES & Guozhu Li \\
\hline 11 & Wuhan & WHN & $30.5^{\circ} \mathrm{N}$ & $114.3^{\circ} \mathrm{E}$ & YES & YES & Guozhu Li \\
\hline 12 & Cebu & CEB & $10.3^{\circ} \mathrm{N}$ & $123.9^{\circ} \mathrm{E}$ & YES & NO & Nagatsuma \\
\hline 13 & Darwin & DWN & $12.5^{\circ} \mathrm{S}$ & $130.9^{\circ} \mathrm{E}$ & YES & YES & Phil Wilkinson \\
\hline \multicolumn{8}{|c|}{ Meteor radar/wind } \\
\hline & Jicamarca & $\mathrm{JCM}$ & $12.0^{\circ} \mathrm{S}$ & $76.9^{\circ} \mathrm{W}$ & Partial & YES & Luiz/Chau \\
\hline \multicolumn{8}{|c|}{ MF radar/wind } \\
\hline 1 & Tirunelveli & $\mathrm{TIR}$ & $8.7^{\circ} \mathrm{N}$ & $77.8^{\circ} \mathrm{E}$ & Partial & YES & Narayanan/Gurubaran \\
\hline 2 & Pameungpeuk & PAM & $7.6^{\circ} \mathrm{S}$ & $107.7^{\circ} \mathrm{E}$ & YES & YES & T. Tsuda/IUGONET \\
\hline \multicolumn{8}{|c|}{ FPI (thermospheric winds) } \\
\hline & Cairi & CAR & $7.5^{\circ} \mathrm{S}$ & $36.4^{\circ} \mathrm{W}$ & YES & YES & Makela/Meriwether \\
\hline \multicolumn{8}{|c|}{ COSMIC satellite data (TEC) } \\
\hline & Equatorial & & \multicolumn{2}{|c|}{ Geomag. \pm 20} & YES & YES & COSMIC \\
\hline
\end{tabular}

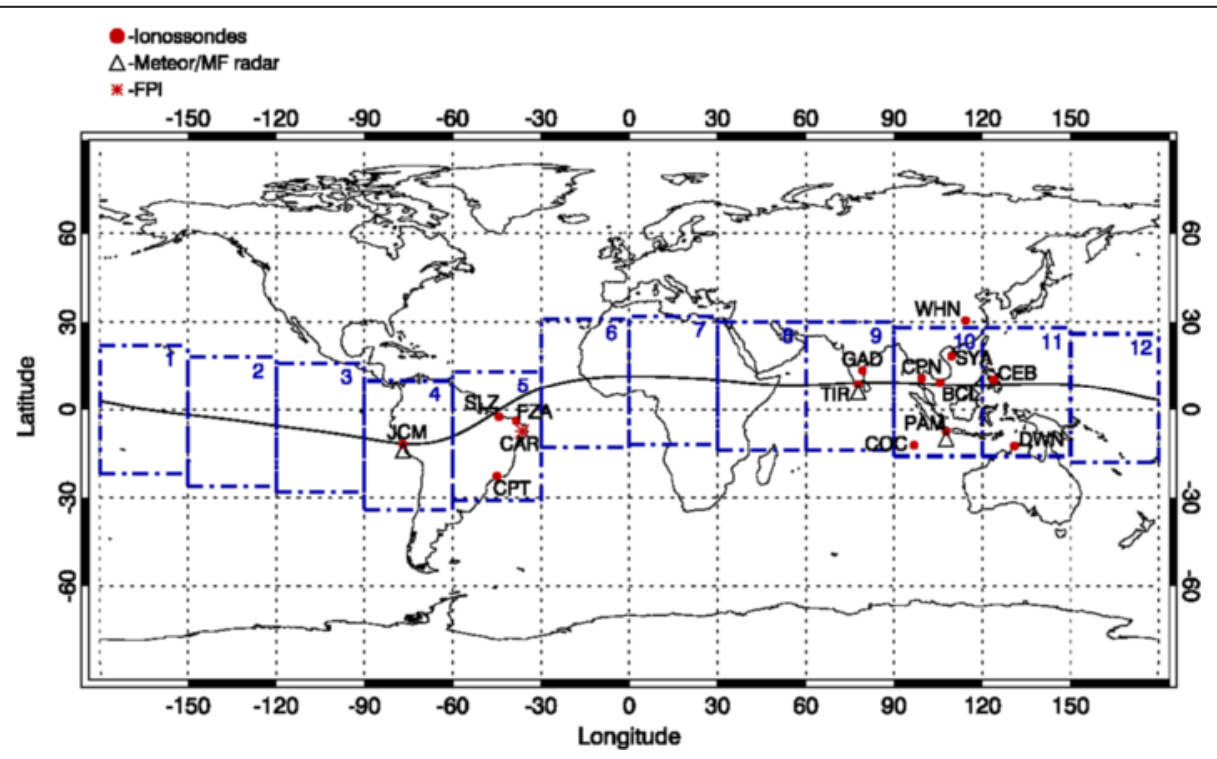

Figure 13 Ground-based observation sites and COSMIC TEC data sampling areas along the geomagnetic equator for LONET campaign. 


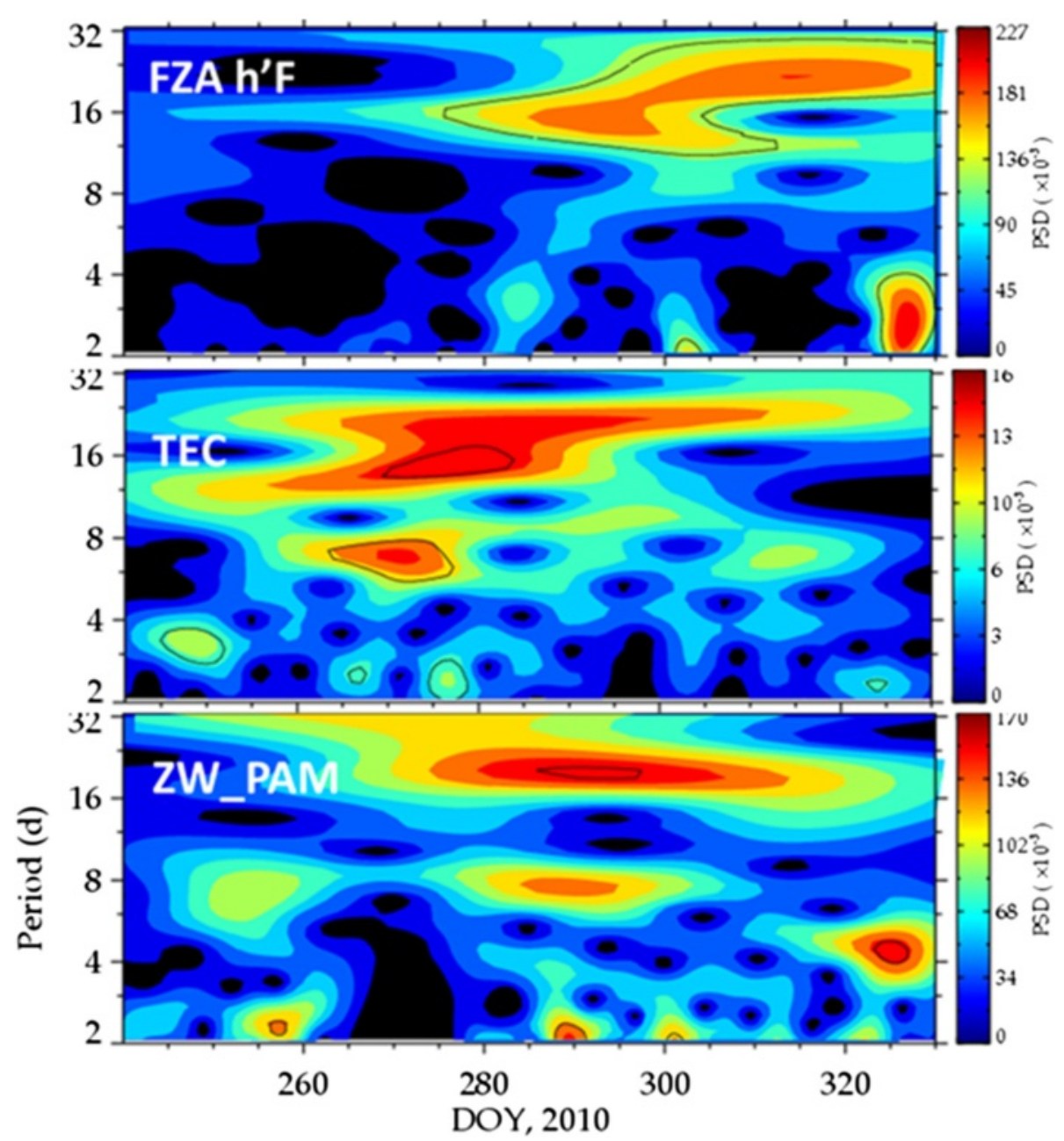

Figure 14 Wavelet spectral density for 2- to 32-day period oscillations during the LONET campaign in 2010. (Top) h'F at Fortaleza, (middle) COSMIC TEC at $345^{\circ} \mathrm{E}$, and (bottom) mesospheric zonal wind (89 km height) at Pameungpeuk.

F activity was observed, and the results were presented in the CAWSES TG4 News letter (vol. 7, page 5, 2012).

\section{Progress of understanding for plasma bubble seeding by GWs}

During the CAWSES-II interval, and in addition to the abovementioned campaigns, several additional interesting results were obtained relevant to the relation between atmospheric waves and ionospheric instabilities. Takahashi et al. (2009) showed a positive correlation between plasma bubble spacing and the spatial scale of mesospheric GW, which were observed simultaneously using airglow imagers in $630 \mathrm{~nm}$ and $\mathrm{OH}$ airglow emissions. Makela et al. (2010) found that the distribution of periodic spacing of equatorial plasma bubble compares favorably to the spectrum of GW-induced traveling ionospheric disturbances (TIDs) measured by Vadas and Crowley (2010) from a similar geographic latitude in the northern hemisphere. These results suggest that the periodic spacing of plasma bubbles are determined by GWs in the lower thermosphere. Several other studies also suggest seeding of plasma bubbles by GWs in the lower thermosphere (e.g., Taori et al. 2010, 2011; Paulino et al. 2011).

Distinct from these small-scale (approximately $100 \mathrm{~km}$ ) GWs, large-scale wave structures (LSWSs, approximately $1,000 \mathrm{~km}$ ) have been considered as another controlling factor of the plasma bubble/equatorial spread F (ESF) generation (e.g., Tsunoda 2005). Thampi et al. (2009) and Tsunoda et al. (2010) demonstrated that a close relationship exists between LSWS and the generation of ESF when the post-sunset rise (PSSR) of the F layer was absent. Tsunoda et al. (2011) showed that the amplification of LSWS in the late afternoon mostly occurs during the post-sunset rise of the equatorial F layer. Narayanan et al. (2014) showed that the occurrences of ionogram satellite traces, which are used as a proxy of LSWS, were followed by ESF in about $71 \%$ of the cases, supporting the view that LSWS appears to be an important parameter in the formation of ESF. 


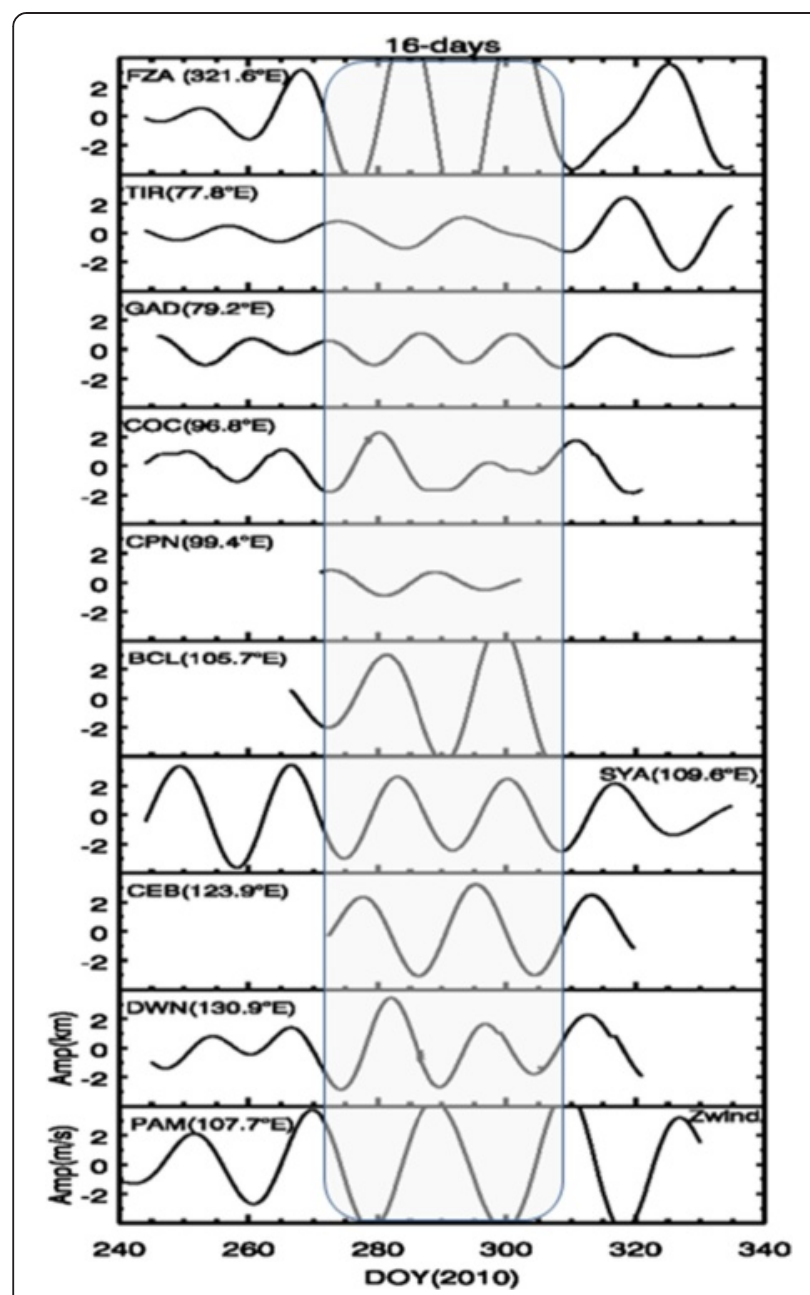

Figure 15 16-day period oscillations of $h^{\prime} F$ and mesospheric winds. 16-day period oscillations of $h^{\prime} F$ and mesospheric winds (bottom) during the LONET campaign period in 2010.

It is also interesting to note that Otsuka et al. (2012) and Shiokawa et al. (2014) reported observations of the dissipation of plasma bubbles in the field-of-view of 630 $\mathrm{nm}$ airglow images due to collision of the bubbles with a mid-latitude MSTID and a large-scale TAD, respectively. In both cases, the bubbles seem to be dissipated by polarization electric field associated with these waves in the ionosphere and thermosphere. This process suggests an additional role of GWs in the ionosphere, namely the suppression of ionospheric instabilities.

Project 3: How do the different types of waves interact as they propagate through the stratosphere to the ionosphere?

A variety of satellite- and ground-based data sets along with model simulations have been used during the CAWSES-II time frame to delineate how large-scale waves propagate through the middle atmosphere to the ionosphere. Several dedicated campaigns, e.g., coordinated ISR observations

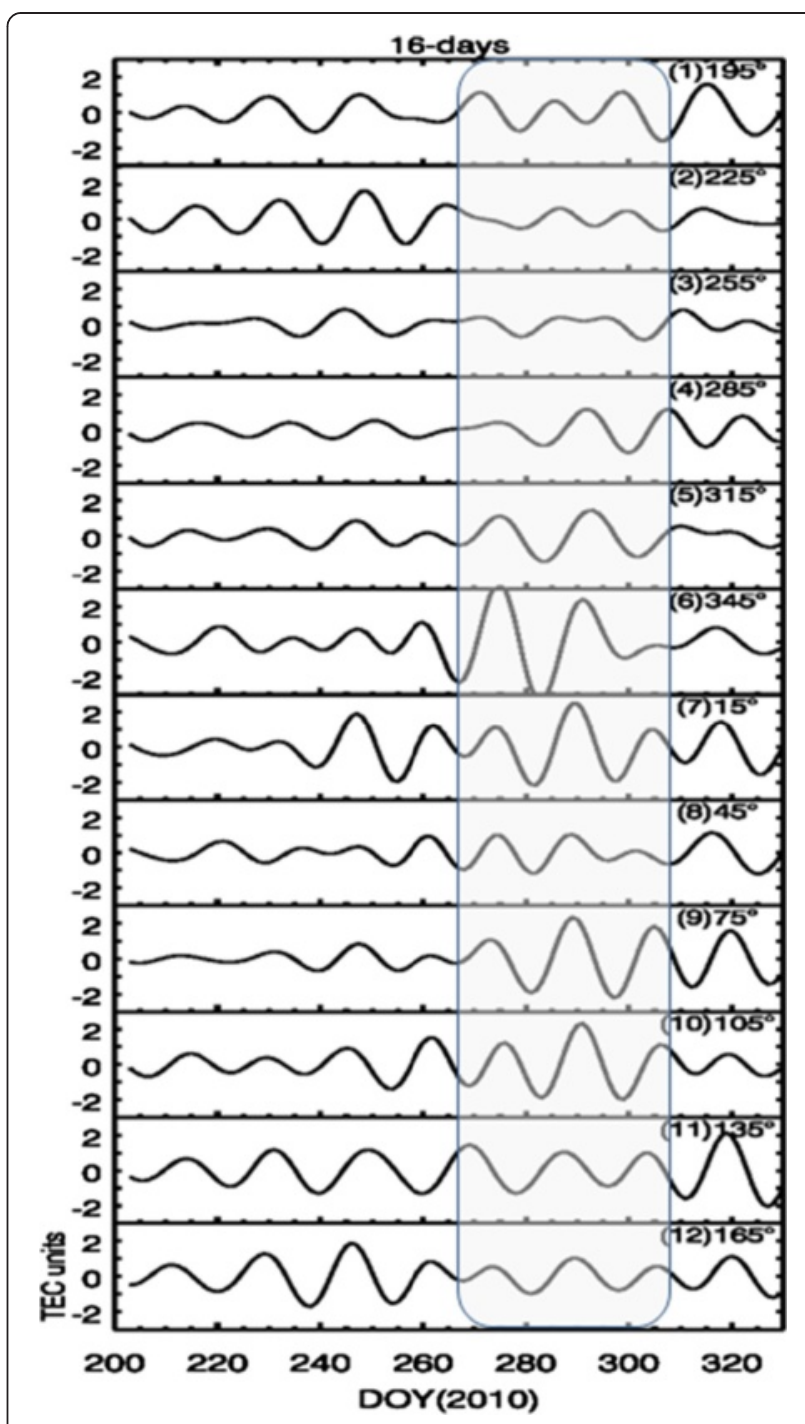

Figure 16 16-day period oscillations of COSMIC TEC during the LONET campaign period in 2010.

during SSWs, and workshops (Table 2) involved the TG4 community and were supported by TG4.

\section{PW signatures in the ionosphere}

For example, the global distribution and the climatological features of the 5- to 6-day planetary waves derived from SABER/TIMED temperature measurements over the height range 20 to $120 \mathrm{~km}$ for a full 6-year period were delineated by Pancheva et al. (2010). This study determined that the 5-day wave, the gravest symmetric wave number 1 Rossby wave, has a vertically propagating phase structure with a mean vertical wavelength of approximately 50 to $60 \mathrm{~km}$, whereas the 6-day wave is an equatorially trapped wave number 1 eastward propagating wave with a mean vertical wavelength of approximately $25 \mathrm{~km}$. Liu et al. (2010a,b) attributed temporal hmF2 'wave-4' variations diagnosed from COSMIC 
data to the interaction of the DE3 with the 5- and 2-day planetary waves. In another study, Mukhtarov et al. (2010) reported on the climatology of stationary planetary waves with zonal wave numbers 1 and 2 observed in SABER/TIMED temperatures for the same period. Further, using COSMIC data on ionospheric parameters, $\mathrm{f}_{\mathrm{o}} \mathrm{F}_{2}$ and hmF2 and electron density at fixed altitudes and the SABER temperature data, Pancheva and Mukhtarov (2012) diagnosed the global-scale spatial and temporal variability of the approximately 23-day zonally symmetric planetary wave during the Northern winter of 2008/2009. The ionospheric oscillations were shown to be forced by planetary waves propagating from below. Pedatella and Forbes (2009b) demonstrated the presence of 16-day waves that were simultaneously observed in the CHAMP electron densities at $350 \mathrm{~km}$, total electron content from global positioning system (GPS) observations, and in SABER temperature data at altitudes of $110 \mathrm{~km}$, indicating that vertically propagating planetary waves induce significant variability in the low latitude F-region ionosphere and that these effects are seen at all longitudes. Recently, Chang et al. (2013) analyzed COSMIC TEC data and found strong stationary planetary wavenumber 4 (SPW4) signals (Figure 17), most likely caused by a strong SPW4 in neutral zonal wind in the E-region (Oberheide et al. 2011b) that in turn is the result of a modulation of the migrating diurnal tide DW1 by the DE3 nonmigrating tide (Hagan et al. 2009).

While the presence of PW signatures in the ionospheric plasma is without dispute and the same neutral/ plasma coupling processes as for the tides (predominantly E-region dynamo modulation, see project 1 ) are thought to apply to PWs as well, the mechanism through which they enter the E-region is still under debate. For example, planetary waves do not penetrate much above $100 \mathrm{~km}$, but instead are thought to impose their periodicities on the ionosphere and thermosphere by modulating the tides and gravity waves that do penetrate to higher altitudes. Other mechanisms include secondary PW forcing. For instance, Lieberman et al. (2013b) using MLS, SABER, and TIDI data, along with Navy Operational Global Atmospheric Prediction System - Advanced Level Physics-High Altitude (NOGAPS-ALPHA) model simulations found observational evidence for wintertime SPWs in the lower thermosphere forced in part by drag imparted by gravity waves that have been modulated by underlying stratospheric SPWs. Their results supported earlier model and case studies by Liu and Roble (2002), Smith (2003), and Oberheide et al. (2006a) that already suggested the plausibility of this mechanism.

\section{SSW impact on the ionosphere and thermosphere}

A prime example for tidal modulation by PWs occurs during sudden stratospheric warmings. An SSW is an extreme atmospheric disturbance event that results in a warmer polar stratosphere and reversed zonal mean flow at mid-latitudes and provides the link between the 'weather' of the polar stratosphere and ionospheric variability close to the geomagnetic equator. As a consequence of publication of the observational evidence for the ionospheric signatures associated with a SSW event by Goncharenko and Zhang (2008), several studies in the recent past have addressed the effect of SSW on the ionosphere due to planetary wave propagation from below. It is now understood that the planetary waves modulate the propagation characteristics of predominantly the semidiurnal migrating tide, enhancing its amplitude, and thereby modulating the E-region ionospheric dynamo, vertical plasma drifts,

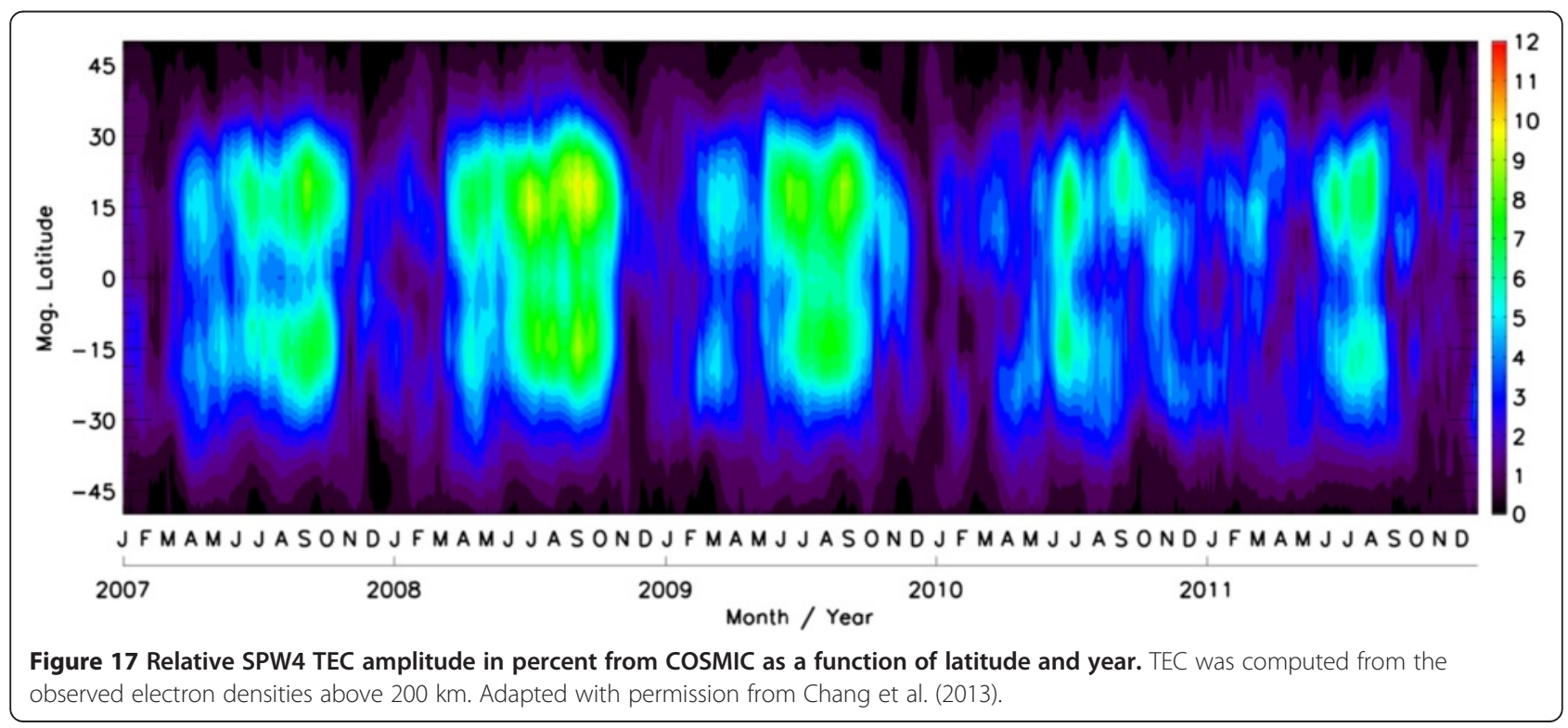


and plasma density in the F-region, in a manner similar to the effects of nonmigrating tides (Liu et al. 2010b; Fuller-Rowell et al. 2011; Chau et al. 2012; Jin et al. 2012). This is exemplified in Figure 18 in which GAIA model simulations are compared with COSMIC and SABER satellite observations during the January 2009 SSW.

A recent ground-based study by Laskar et al. (2014) conducted in the Indian sector suggests that the 16-day modulation of the semidiurnal tide is particularly strong during strong SSW events and as such exerts a significant impact on ionospheric variability even during high solar activity. Although SSWs only happen at most a few times per year, they nevertheless provide an excellent opportunity to test current theories of neutral-plasma coupling on a global scale and for testing the predictive capabilities of space weather models, as SSWs can be forecasted on a 1-week timescale (Fuller Rowell et al. 2011; Wang et al. 2014).

Pancheva and Mukhtarov (2011) presented for the first time the global spatial (latitude and altitude) structure of the mean ionospheric response to SSW events during winters of 2007/2008 and 2008/2009 using COSMIC $f_{\mathrm{o}} \mathrm{F} 2$ and $h_{\mathrm{m}} \mathrm{F} 2$ and electron density data at fixed altitudes. Several studies were carried out to understand the processes underlining the SSW control of the electrodynamics at low latitudes. Chau et al. (2009) provided strong evidence indicating that the distinctive behavior of the vertical ExB drifts over the magnetic equator during daytime was associated with a minor SSW. Following this work, Chau et al. (2010) identified SSW signatures in several ionospheric parameters using the incoherent scatter radar (ISR) electron density and temperature measurements from the Arecibo Observatory, as well as relative TEC variations derived from a dual-frequency GPS receiver. To examine the response of the mid-latitude ionosphere to SSW, Goncharenko et al. (2013) undertook a case study of the day-to-day variability in the ion temperature at altitudes between 200 and $400 \mathrm{~km}$ and detected disturbances at tidal periods as well as at non-tidal and multi-day periods. As planetary waves are not expected to reach middle and upper thermospheric altitudes, as noted in the previous subsection, these results have once again raised questions about the underlying mechanisms coupling the lower and upper atmosphere.

A TIME-GCM simulation by Liu and Roble (2002) revealed that the resonant SPW amplification prior to the peak warming causes a deceleration of the mean wind in the high latitude winter stratopause and mesosphere and reverses to westward with a critical layer near the zero wind line. This changes the filtering of gravity waves by allowing more eastward GW to propagate into the MLT

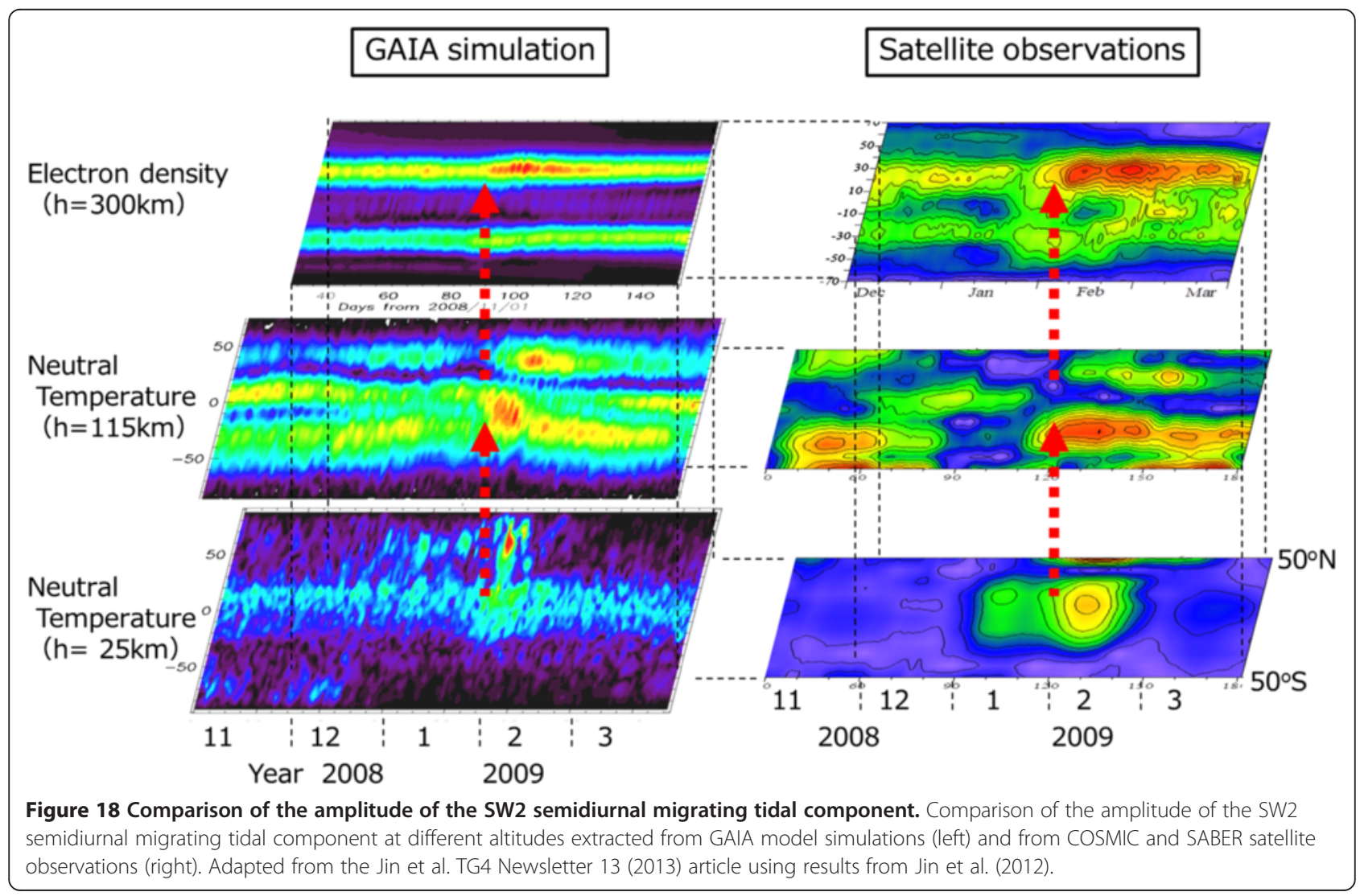


region and a resulting change of the meridional circulation in the upper mesosphere from poleward/downward to equatorward/upward with corresponding stratospheric warming, mesospheric cooling, and thermospheric warming patterns in the mean temperatures at high latitudes during SSWs. At low latitudes, this temperature pattern reverses and produces a thermospheric cooling and consequently a thermospheric density decrease at a fixed altitude by reducing the scale height.

\section{SSW and lunar tides}

Recent ground-based and satellite magnetometer observations in conjunction with other ionospheric measurements have provided insights of how lunar tidal modulation during SSW events can drive the spatio-temporal variabilities of the equatorial electrojet and the electrodynamics (Fejer et al. 2010, Park et al. 2012, Yamazaki et al. 2012). However, Stening (2011) argued against a strong lunar tidal contribution to the observed variability during SSWs since strong lunar tidal signals exist during non-SSW periods so that these correlations might be coincidental. Fuller-Rowell et al. (2011) indeed found SSW-induced phase shifts in the semidiurnal solar tide consistent with an apparent lunar tidal signal using WAM simulations, but it should be noted that the model did not include the semidiurnal lunar tide as an input. Wang et al. (2014) in a coupled WAM/ionosphere model simulation also found a phase shift of the SW2 solar component during SSWs caused by SSWinduced variability in its main source, stratospheric ozone, and/or additional middle atmosphere circulation changes. On the other hand, Pedatella et al. (2014) reported notable enhancements of the semidiurnal lunar tide during SSW events in WACCM-driven TIME-GCM simulations and a better agreement with COSMIC electron density observations when the lunar tide was included in the model. It must thus be concluded that the impact of lunar tides on ionospheric variability during SSWs is not yet finally resolved and requires further studies by the aeronomy community over the coming years. It should also be noted that there is increasing evidence that the ionospheric plasma variability during SSWs is not solely caused by E-region electric field variability but also by variability in F-region meridional neutral winds and thermospheric composition changes (e.g., Pedatella et al. 2014). This is consistent with the earlier modeling work by England et al. (2010) and Maute et al. (2012) that was focused on nonmigrating tides.

\section{SSW and GW}

Small-scale variability of the upper atmosphere driven by major atmospheric disturbances from below like SSW has also gathered attention recently. Adopting a first principle nonlinear hydrostatic GCM extending from the lower atmosphere to the thermosphere, Yiğit et al.
(2014) investigated the influence of small-scale gravity waves originating in the lower atmosphere on the variability of the high latitude thermosphere during an SSW event. The numerical experiments revealed that the gravity wave penetration into the thermosphere increased the momentum deposition rates above $150 \mathrm{~km}$ in the high latitude northern hemisphere by up to a factor of 3 to 6 during the warming. This demonstrates that gravity wave-induced variations during SSWs constitute a significant source of high latitude thermospheric variability.

\section{Project 4: How do thermospheric disturbances generated by auroral processes interact with the neutral and ionized atmosphere? \\ Upper thermosphere}

From the CHAMP satellite observations, Lühr et al. (2004) showed the existence of strong heating in the cusp (and/or near the cusp) region. This heating causes upwelling of the air and enhancement of the neutral mass density in the altitude region of about $400 \mathrm{~km}$. In addition, the CHAMP satellite observed some thermospheric disturbances during geomagnetically disturbed periods. For example, Ritter et al. (2010) identified substorm-related thermospheric density and wind disturbances from the CHAMP observations. They reported mass density enhancements, a density bulge propagating as a traveling atmospheric disturbance (TAD), and wind variations during a substorm event. Liu and Yamamoto (2011) reported geomagnetic storm effects on the formation and characteristics of the mid-latitude summer nighttime anomaly (MSNA), which is a phenomenon during which the diurnal variation of the plasma density maximizes at night instead of day. They pointed out the role of the effective neutral wind in the formation of MSNA. Some results obtained from the CHAMP observations were summarized in the review paper presented by Lühr et al. (2012).

Vickers et al. (2013) developed a new technique to obtain thermospheric neutral density at approximately 350 $\mathrm{km}$ altitude from incoherent scatter radar data. In situ comparisons with the CHAMP satellite show good agreement. Vickers et al. (2014) used this technique on the EISCAT Svalbard radar for the period 2000 to 2013 and showed that F10.7 solar irradiance is a very good proxy for thermospheric density variations with only a small seasonal dependence. In addition, the long-term trend of declining thermospheric density was observed.

Co-rotating interaction region (CIR) and subsequent high speed solar wind stream (HSS) is one of important causes of the thermospheric disturbances in association with auroral phenomena during a solar minimum period (e.g., Thayer et al. 2008; Lei et al. 2011; Verbanac et al. 2011). Pedatella and Forbes (2011) described responses of the ionosphere and thermosphere to high speed solar 
wind streams from the DMSP F13 satellite observations and the Thermosphere-Ionosphere-Electrodynamics General Circulation Model (TIE-GCM) simulations. They concluded that the disturbance dynamo would be an important mechanism for driving the electrodynamic response at dawn and dusk to recurrent geomagnetic activity driven by HSS. Gardner et al. (2012) investigated the HSS heating effects from numerical simulations and observations with the EISCAT Svalbard radar (ESR) and PFISR. They showed that the HSS heating can cause temperature enhancement as high as $100 \mathrm{~K}$ at high latitudes, but the global increase in thermospheric temperature would be low.

Coronal mass ejections (CMEs) are also one of the important causes of the geomagnetic storms. The thermospheric density variations during CME- and CIR-induced geomagnetic activities were compared by Chen et al. (2012). The total changes in the thermospheric density observed during periods of CIR storms were greater than those of the CME storms because the CIR storms lasted longer than CME storms, while the CME storms were stronger than the CIR storms on average.

For smaller scale waves, several airglow imagers investigated thermospheric and ionospheric waves identified as MSTIDs near the auroral zone through the $630 \mathrm{~nm}$ airglow emissions at altitudes of 200 to $300 \mathrm{~km}$. Kubota et al. (2011) reported characteristics of MSTIDs observed by an airglow imager at Alaska. They concluded that these southwestward-moving MSTIDs are not caused by ionospheric instabilities, as usually suggested at middle latitudes, but are likely to be caused by auroral disturbances as TADs because the observed background thermospheric wind was poleward, stabilizing the ionospheric instability. On the other hand, Shiokawa et al. (2013) reported similar southwestward-moving MSTIDs over Norway and northern Canada and suggested that they are caused mainly by the Perkins and E-F coupling instabilities (Perkins 1973; Yokoyama et al. 2009) similar to those at middle latitudes and that an additional source by atmospheric gravity waves from lower altitudes also comes into play. Shiokawa et al. $(2012,2013)$ reported sudden movements of these MSTIDs at subauroral latitudes concurrent with auroral activity, indicating instantaneous penetration of auroral electric fields to subauroral latitudes.

\section{MLT region}

Dynamics and Energetics of the Lower Thermosphere in Aurora (DELTA) and DELTA-2 campaigns were carried out in December 2004 and January 2009, respectively. Simultaneous observations with the EISCAT radar, FPI, and sounding rockets were successfully made during the two campaigns. For example, Kurihara et al. (2009) identified temperature enhancement in the lower thermosphere in association with the auroral heating during the
DELTA campaign. Oyama et al. (2010) also reported lower thermospheric wind fluctuations measured with an FPI during pulsating aurora at Tromsø, Norway, in the period of the DELTA-2 campaign (Figure 19). Some studies concerning the occurrence of atmospheric gravity waves in the polar thermosphere in response to auroral activity were summarized in the review paper of Oyama and Watkins (2012).

Following initial studies of thermospheric meso-scale variability using tristatic Fabry-Pérot interferometer (FPI) observations at EISCAT (Aruliah et al. 2004, 2005), the neutral wind variations in the vicinity of an auroral arc were studied by some researchers. Oyama et al. (2009) showed spatial evolution of frictional heating and increases in ion flow and temperature in the vicinity of an auroral arc from observations with the Sondrestrom incoherent-scatter radar and the Reimei satellite. They clarified localized ionospheric structures associated with localized soft particle precipitation or F-region ionization, suggesting the presence of a narrow thermospheric wind shear of about $10 \mathrm{~km}$ width. Kosch et al. (2010) reported the first observational results of the E-region neutral wind fields and their interaction with auroral arcs during geomagnetically quiet conditions at Mawson, Antarctica, with a scanning Doppler imager (SDI). The $144^{\circ}$ field-of-view Doppler images of the sky over Mawson are shown in Figure 20. They found that E-region wind could rotate $90^{\circ}$ within approximately $10 \mathrm{~min}$ when close to (within approximately $50 \mathrm{~km}$ ) of an auroral arc and then recover to the background flow when the arc disappeared. The F-region wind remained unaffected. This was attributed to the electric field associated with auroral arcs causing localized strong ion drag. Anderson et al. (2011) performed bistatic FPI observations of F-region thermospheric vertical winds in Antarctica. They found strong upward winds poleward of the auroras as well as correlated vertical wind responses over horizontal distances of approximately 150 to $480 \mathrm{~km}$.

Kosch et al. (2011) made meso-scale observations of the ionosphere and thermosphere with the EISCAT Svalbard radar and SDI, partly in the vicinity of an auroral arc, within the polar cap at approximately $110 \mathrm{~km}$ altitude. They found that Joule heating had a meso-scale (approximately $64 \mathrm{~km}$ ) spatial variability of up to $>100 \%$ even during steady-state geomagnetic conditions. Figure 21 shows the spatial distribution of Joule heating in $22.5^{\circ}$ sectors about the EISCAT Svalbard radar projected to $110 \mathrm{~km}$ for 23:36 to 23:54 UT on 2 February 2010. They estimated the E-region ion-neutral collision frequency at $112.8( \pm 0.8) \mathrm{km}$ altitude by combining E- and F-region ion flow with E-region neutral flow data and found good agreement with the MSIS model. Anderson et al. (2013) also made observations of the ionosphere and thermosphere with PFISR and SDI. They found the 


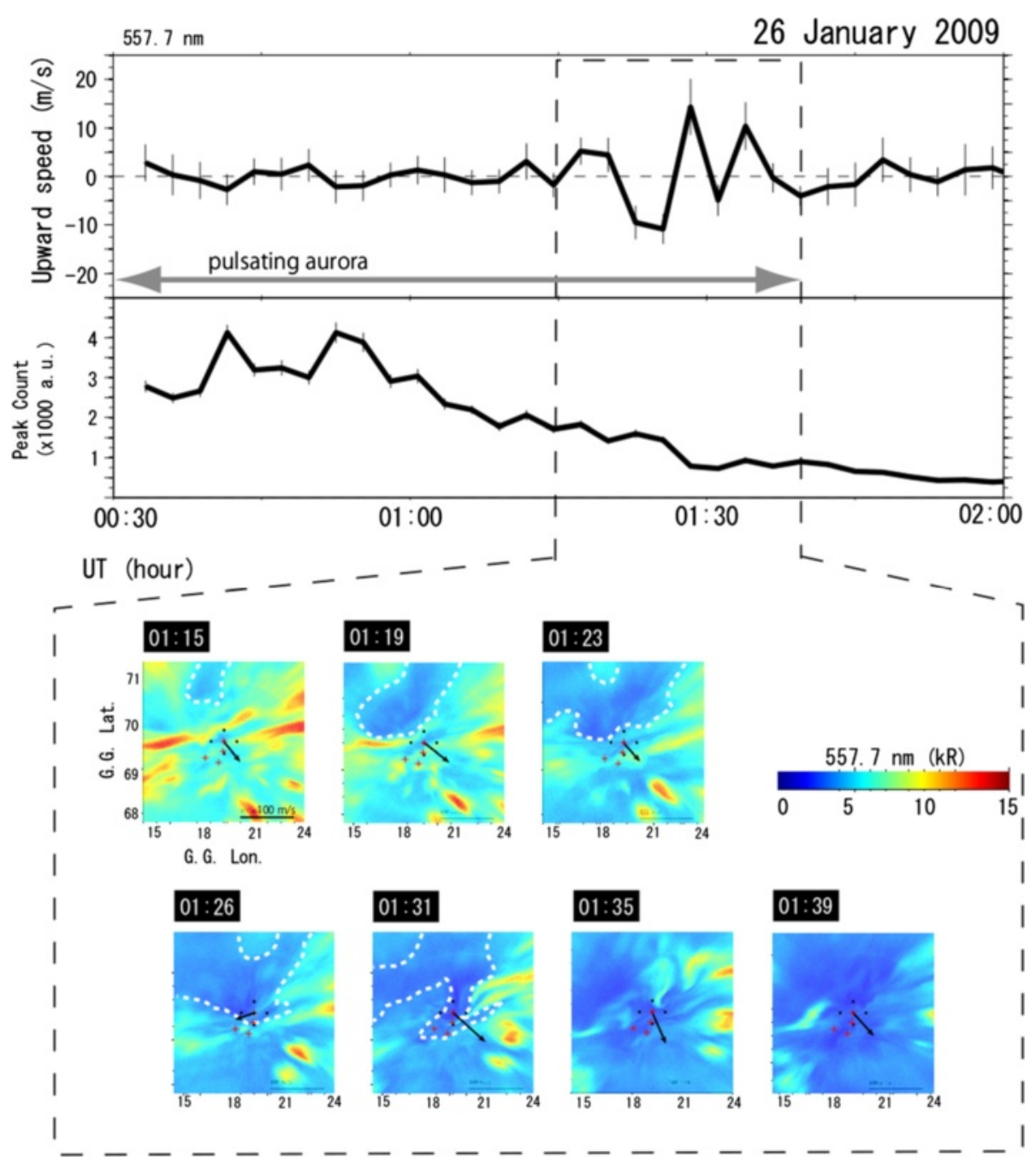

Figure 19 Temporal variations in the vertical wind speed and the fringe peak count at the zenith. Top and middle panels show the temporal variations in the vertical wind speed and the fringe peak count at the zenith, respectively, measured with the FPI (557.7 nm) from 00:30 to 02:00 UT on 26 January 2009. Vertical bars are the 2 sigma uncertainty (see in the text of Oyama et al. 2010). The bottom color panels show the horizontal aurora images taken with the ASC at $557.7 \mathrm{~nm}$ from 01:15 to 01:39 UT during pulsating aurora (corresponding time interval is marked by black dashed line in the top two panels). The color scale of optical intensity is shown at the right middle. These images are mapped in geographic coordinate assuming the peak emission height is $110 \mathrm{~km}$. The five black dots and the four red crosses indicate the location of the FPI and the EISCAT UHF radar observation positions, respectively. The black arrows correspond to the horizontal component of the FPI-derived neutral wind velocity (the scale is presented at the right bottom corner of the first panel from the left). White dashed lines in the colored panels are drawn to easily identify the darker area. Adapted with permission under Creative Commons Attribution 3.0 License from Oyama et al. (2010).

neutral wind dynamo contribution to Joule heating was $36 \%$ to $64 \%$ on average and was positive when the horizontal magnetic field perturbation was weak $(|\Delta \mathrm{H}|<$ approximately $40 \mathrm{nT}$ ) and vice versa. They estimated the F-region ion - neutral collision frequency at $260 \mathrm{~km}$ altitude using the ambipolar diffusion equation - and also found good agreement with the MSIS model.

Recently, Xu et al. (2013) showed longitudinal variations of the thermospheric temperature from satellite observations with SABER and Michelson Interferometer for Passive Atmospheric Sounding (MIPAS) and simulations with TIE-GCM. Their simulations clarified that auroral heating would cause the observed longitudinal temperature variations. In addition, the satellite observations indicated that impacts of auroral heating on the neutral atmosphere can penetrate down to about $105 \mathrm{~km}$. The lidar observations are quite useful to study thermospheric disturbances in the MLT region. For example, Chu et al. (2011) observed temperature enhancements caused by Joule heating and fast gravity waves propagating from the lower atmosphere in the neutral Fe layers (110 to $155 \mathrm{~km}$ ) in Antarctica. Tsuda et al. (2013) showed decreases in sodium density in association with auroral particle precipitation from 

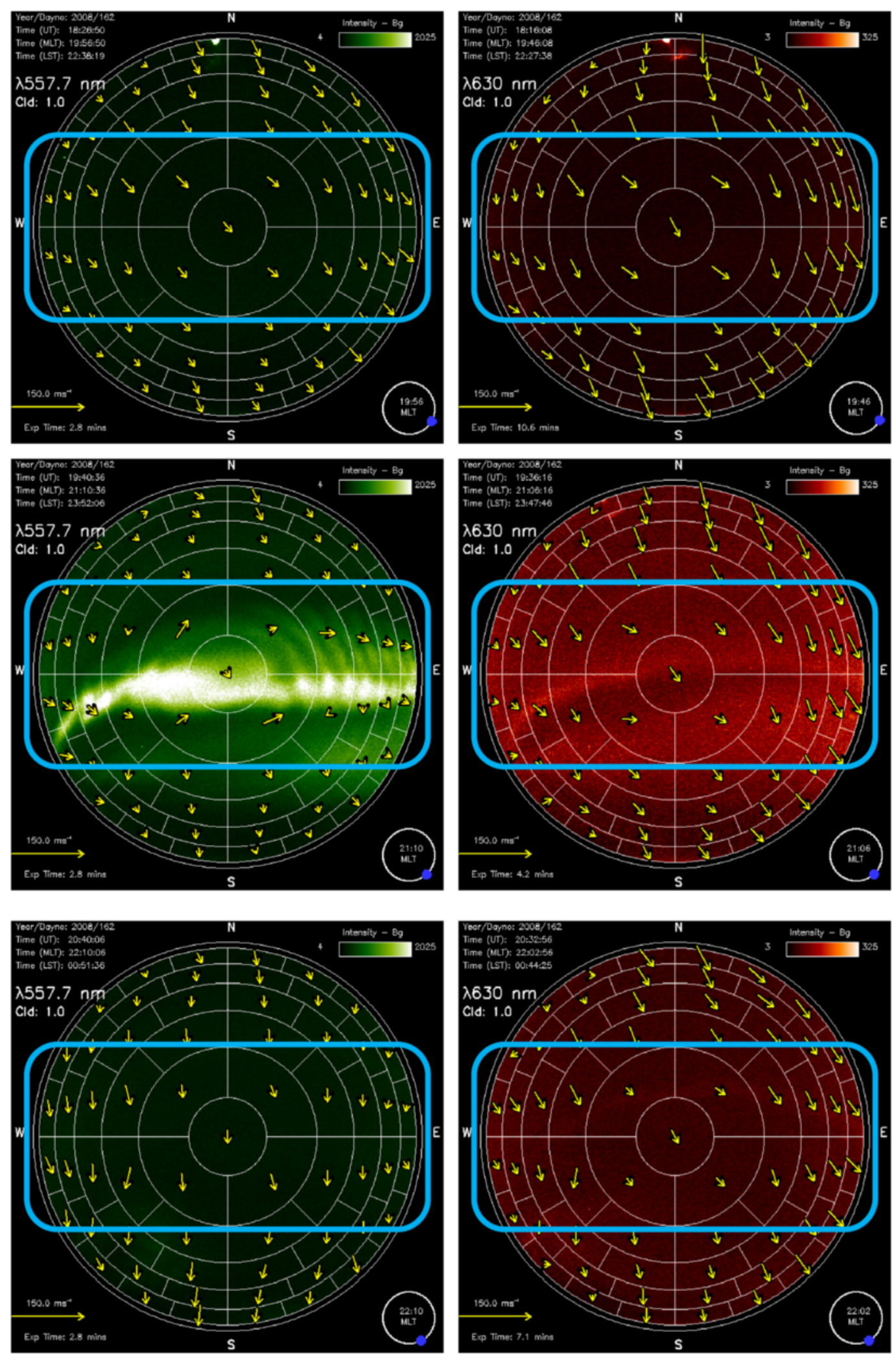

Figure $\mathbf{2 0}$ (See legend on next page.) 
(See figure on previous page.)

Figure 20 The $144^{\circ}$ field-of-view Doppler images of the sky over Mawson. The right column shows F layer $630 \mathrm{~nm}$ Doppler images, the left column shows E layer $557.7 \mathrm{~nm}$ Doppler images on 10 June 2008. Each plot is labeled with UT. The optical intensity is not calibrated. The optical data are plotted in geographic coordinates with horizontal wind vectors overlaid for each zone (yellow). The wind vectors are centered on their measurement points. The vector for the zenith sector shows the average wind field, not the vertical wind. The top row (18:16 to 18:27 UT) shows before the arc appeared, the middle row (19:36 to 19:40 UT) shows when the arc appeared, and the bottom row (20:33-20:40 UT) shows after the arc disappeared. The blue box highlights the region of interest.

simultaneous and common volume observations by the EISCAT VHF radar and a sodium lidar at Tromsø, Norway.

\section{Model simulations in association with auroral/high latitude phenomena}

Some general circulation models (GCMs) have been developed to understand the energetics, dynamics, and composition variations of the upper atmosphere. These simulations clarified disturbances in the polar ionosphere and thermosphere in association with auroral activity and/or high latitude energy inputs. For example, Qian et al. (2010) simulated thermospheric response to recurrent geomagnetic forcing with the NCAR TIE-GCM. Neutral density and nitric oxide (NO) cooling rates were simulated for the declining phase of solar cycle 23. The simulated results were compared to neutral density derived from satellite drag and to NO cooling measured by TIMED/SABER. Gardner and Schunk (2011) performed numerical simulations to investigate characteristics of the large-scale gravity waves with a high-resolution global thermosphere-ionosphere model which can represent global distributions of mass density, temperature, and all three components of the neutral wind at altitudes from 90 to $500 \mathrm{~km}$ without the assumption of hydrostatic equilibrium. They noted that a secondary wave was generated which propagated around the entire globe, while the original gravity wave was localized. Deng et al. (2011) also investigated nonhydrostatic effects in the thermosphere from Global Ionosphere Thermosphere Model (GITM). Their simulations demonstrated that most of the nonhydrostatic effects at high altitudes $(300 \mathrm{~km})$ arise from sources below $150 \mathrm{~km}$ and propagated vertically through the acoustic wave. Basic structures of the polar ionosphere and thermosphere during solar minimum and geomagnetically quiet periods were investigated by Fujiwara et al. (2012) from the EISCAT Svalbard radar observations (March 2007 to February 2008) and simulations with a whole atmosphere GCM. Their results indicated that both the ions and neutrals would show larger variations than those described by the empirical models, suggesting significant heat sources in the polar cap region even under solar minimum and geomagnetically quiet conditions. In addition to the global model simulations, de Larquier et al. (2010) performed one- and twodimensional numerical simulations with a finite-difference time-domain (FDTD) model to provide quantitative interpretation of the recently reported infrasound signatures from pulsating aurora. They discussed pressure perturbations caused by particle heating due to pulsating aurora (heat source is located between 90 and $110 \mathrm{~km}$ on average). The simulation results were roughly an order of

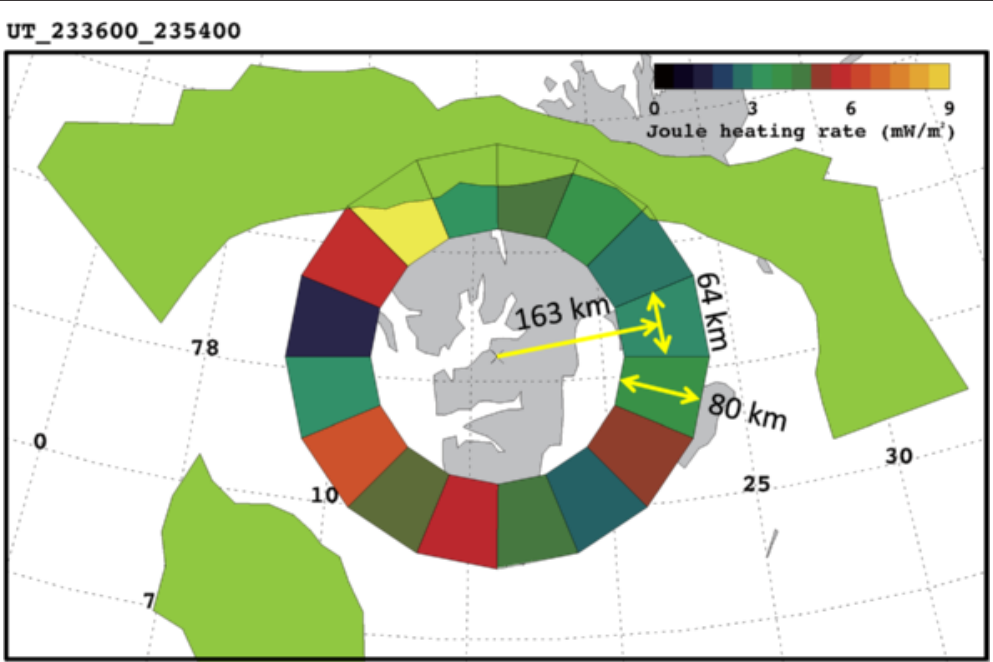

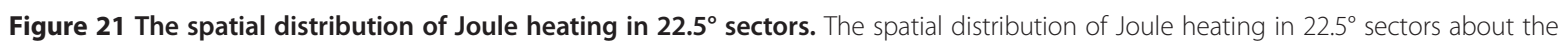

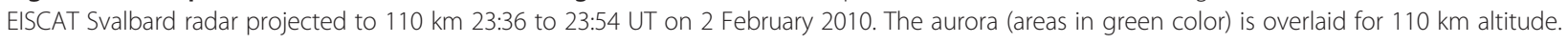


magnitude smaller than those observed, suggesting the need for an additional source, e.g., Joule heating.

\section{Conclusions}

\section{Scientific outcome and challenges}

Overall, TG4 brought together the historically separate neutral atmosphere and plasma communities in a way that allowed for much progress in understanding how neutral variability originating in the lower atmosphere impacts and interacts with Earth's ionosphere, from low to polar latitudes and from the troposphere to the F-region. For example, the role of waves due to convection, polar stratosphere dynamics, or auroral processes in causing substantial ionospheric variability through dynamo processes and Rayleigh-Taylor instabilities is now much better understood than before. This was achieved through a combination of dedicated campaign activities and workshops resulting in four special issues in the peerreviewed literature (Table 2). The aeronomy community is well on its way to separating ionospheric variability introduced by driving from below and from the magnetosphere and Sun above, an essential task toward achieving predictability of space weather. In this respect, it is important to note that the solar activity at the beginning of the CAWSES-II period was extremely quiet, allowing the pure effects from the lower atmosphere to be observed in isolation without disturbances from above.

There are a number of critically important open questions toward the goal of achieving space weather predictability. Significant amounts of variability remain unexplained and/ or are very difficult to detect and interpret, for example, the imprints of convectively forced gravity waves in the thermosphere. Short-term tidal variability in the neutrals and plasma is largely unknown because of the lack of suitable satellite data since local time coverage by a single satellite is limited. It is not clear what is more important: wave propagation into the thermosphere and then into to the ionosphere; or electrodynamic coupling between the E- and F-region and then into the thermosphere. The dynamics community still knows little about interactions between the various types of waves (tides, PWs, and GWs) and the mean flow. A major observational and technological challenge is the lack of global wind observations, day and night, throughout the 120 to $400 \mathrm{~km}$ region.

As overviewed below, new space-borne and groundbased assets, along with progress in geospace modeling, will help to close this knowledge gap that is also targeted through elements of SCOSTEP's new VarSITI program.

\section{Program outreach}

As a dedicated effort of the international scientific community, and in accordance with SCOSTEP's mission not only to run scientific programs but also to promote solar-terrestrial physics and dissemination of the derived knowledge for the benefit of society, Task Group 4 published a quarterly newsletter. Each newsletter was about eight pages long with updates on recent campaign activities, short news, and a portrait of a young scientist. All articles were written to be understandable for non-specialist and published on the task group wiki (www.cawses.org/ wiki/index.php/Task_4) and through an extensive mailing list. A total of 13 issues have been published with 64 articles from authors from 20 different countries, including 10 articles featuring young scientists. TG4 also organized and/or supported 12 dedicated workshops and special sessions and held annual business meetings during major conferences.

\section{New and future satellite missions}

Space agencies and national science foundations in the U.S., Europe, and Asia by now recognize the importance of lower atmosphere driving of the ionosphere-thermosphere system not only as a domain of compelling scientific inquiry but also as highly relevant for understanding and predicting space weather; a task highly relevant for technological societies.

In the United States, the Decadal Survey on Solar and Space Physics 2013 to 2022 conducted by the National Academy of Sciences (National Research Council 2013) recognized the realization that weather systems in the troposphere impact space weather through tides and gravity waves as one of the significant discoveries in the past decade, making the comprehensive understanding of the variability in space weather driven by loweratmosphere weather on Earth' its second highest priority and recommended a dedicated satellite constellation (DYNAMIC) to be launched around the year 2020. While NASA budget constraints may delay the implementation of DYNAMIC; two new satellite missions dedicated to ionosphere-thermosphere physics, ICON and GOLD, will be launched in 2017. Both ICON and GOLD can be seen as pathfinder missions for DYNAMIC. ICON will collect data from a low Earth orbit to compare the impacts of direct solar driving and lower atmosphere driving on variability in the ionosphere/ thermosphere system, and GOLD will image the thermosphere from a geostationary orbit, allowing for an unprecedented global view of short-term variability.

A very exciting new mission, launched on 22 November 2013, is the European Space Agency (ESA) Swarm mission. Swarm is a unique three satellite constellation with two satellites orbiting at $480 \mathrm{~km}$ and one at $510 \mathrm{~km}$ to measure Earth's magnetic field, the electric field in the ionosphere, and thermospheric density and winds. See the special issue in Earth, Planets and Space on Swarm Science Data Processing and Products - the Swarm Satellite Constellation Application and Research Facility (2013) for details. Each of the identical Swarm satellites has a vector and scalar magnetometer, a 
Langmuir probe, an accelerometer, and GPS instrumentation on board, similar to the tremendously successful CHAMP satellite. During its anticipated 10-year mission, the Swarm data will allow the ionosphere/thermosphere community to obtain an unprecedented view of smallscale structures in the thermosphere and the ionospheric plasma.

Due to the success of COSMIC (a particularly important dataset for the ionosphere/thermosphere community because of its global electron density profiles from radio occultation), the United States and Taiwan will launch COSMIC-2 between 2015 and 2018. COSMIC-2 consists of six satellites in a low-inclination orbit (launch in 2015) and another six satellites in high inclination orbits (launch in 2018).

Along with emerging cubesat and nanosat capabilities, these new space-borne assets will form the backbone of studying the signatures and impact of lower atmosphere variability versus magnetosphere/solar-driven variability in the next decade. Their synergistic use will most likely allow the community to make significant progress toward understanding geospace as a system and also toward predictability of space weather, a significant need for a technological society. A particular challenge, however, will remain: global thermospheric winds throughout the whole thermosphere during day- and nighttime; dataset airglow interferometers cannot provide. The implementation of new emerging technologies, such as the Doppler wind and temperature sounder (DWTS; Gordley and Marshall 2011; Lieberman et al. 2012), will be needed.

\section{New ground-based assets}

Ground-based facilities are powerful tools to measure vertical coupling from the atmosphere to geospace. They are basically radio techniques (various types of radars, ionosondes, satellite beacon receivers including Global Navigation Satellite System (GNSS) receivers, natural/artificial wave receivers, and magnetometers) and optical techniques (imagers and interferometers for airglow and aurora; and lidars). Figure 22 summarizes the altitude ranges and measurement parameters of various ground-based techniques. Because a single instrument covers only a certain range of altitudes and can measure a limited set of physical parameters, it is essential to combine several types of instruments at the same place to understand the connection from the troposphere to geospace. Multi-point networks of these various instruments are becoming available, providing global information of these parameters, e.g., Yumoto (2011) - MAGDAS and Yizengaw and Moldwin (2009) - AMBER for magnetometers, Makela et al. (2009) - RENOIR, Shiokawa et al. (2009) - OMTIs, Makela et al. (2012) - NATION, and Meriwether et al. (2014) - Peruvian FPIs for optical instruments, and Cohen et al. (2010) - AWESOME for LF/VLF receivers. It is also important to combine these ground-based observations with satellite measurements to separate temporal and spatial variations.

One of the great progress of ground-based observation during CAWSES-II was that the multi-point GNSS receiver network is becoming a powerful tool to provide

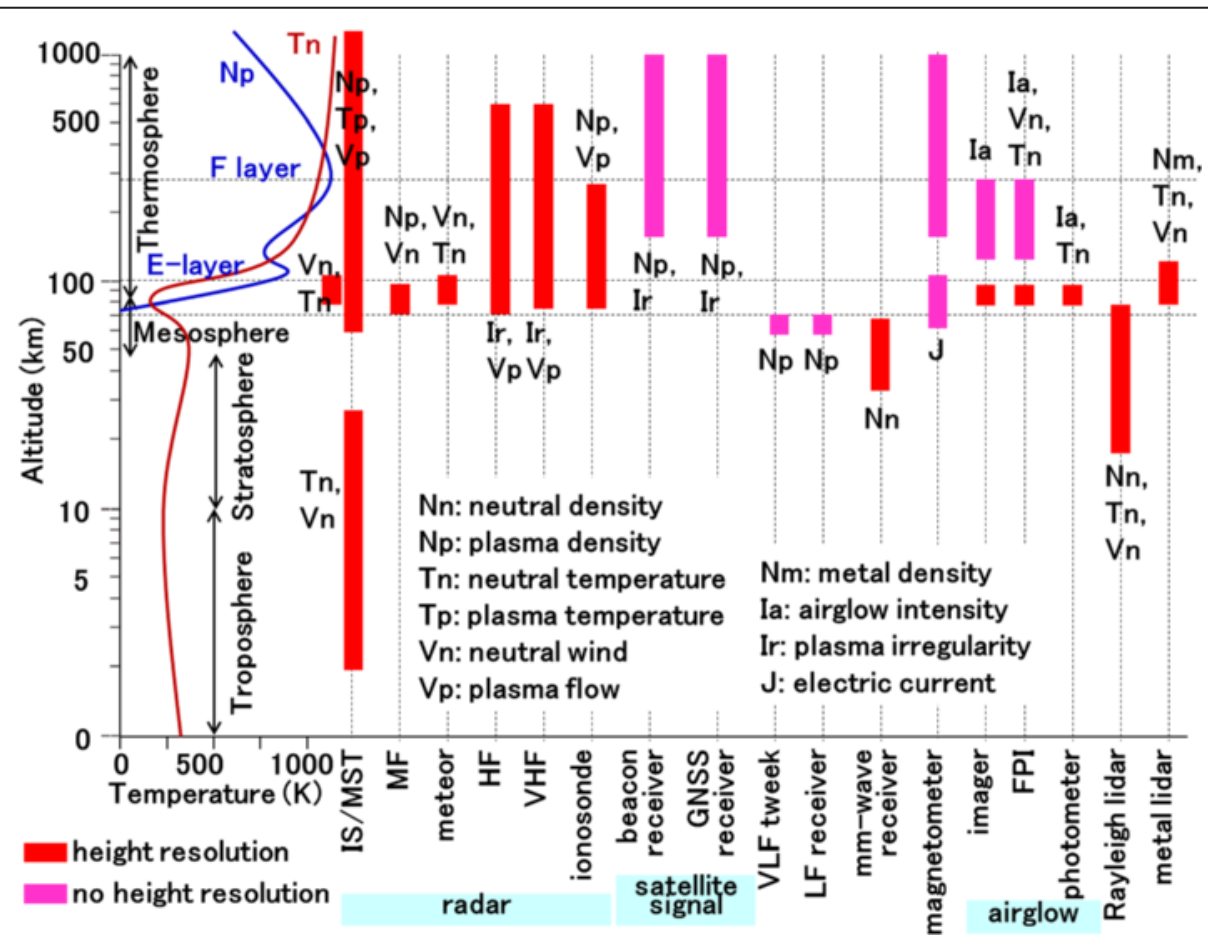

Figure 22 Various ground-based instruments to observe the upper atmosphere, their altitude ranges, and parameters of measurements. 
two-dimensional images of the ionospheric total electron content in the spatial resolution of less than approximately $100 \mathrm{~km}$, as shown in Figure 2 as a striking example of tsunami- and tornado-induced gravity wave penetration to the ionosphere (Tsugawa et al. 2011; Nishioka et al. 2013). Such high-resolution TEC maps become available not only over Japan and US, but also in other places, e.g., over South America (Takahashi et al. 2014) and Europe (Otsuka et al. 2013). The number of GNSS receivers will grow further even after the CAWSES-II era and will become an important facility to monitor ionospheric disturbances.

The widest altitude coverage from the troposphere to the ionosphere can be achieved by powerful facilities of incoherent scatter (IS)/mesosphere-stratosphere-troposphere (MST) radars. Currently, major facilities of IS/ MST radars are available at Resolute Bay (RISR), Poker Flat (PFISR), Sondrestrom, Milstone Hill, Arecibo, and Jicamarca in the American longitudinal sector; Irkutsk, Shigaraki (MU), Wuhan, Gadanki, and Kototabang (EAR) in the Asian sector; and Svalbard (ESR), Scandinavia (EISCAT), Andøya (MAARSY), Kharkov, and Syowa (PANSY) in the European sector. The EISCAT radar will be renewed into the EISCAT_3D radar (Wannberg et al. 2010) to obtain three-dimensional information of plasma-neutral interaction in the auroral ionosphere/thermosphere. This renewal will also stimulate measurements of tropospheric and stratospheric parameters using its powerful facilities. The Equatorial Atmosphere Radar (EAR) is planned to be renewed to the EMU (Equatorial Middle and Upper atmosphere) radar with more than five times larger transmission power to perform IS observations of the ionosphere.

\section{VarSITI - SCOSTEP's 2014 to 2018 program}

The new 2014 to 2018 SCOSTEP program Variability of the Sun and Its Terrestrial Impact (VarSITI) will focus on the unusual low solar activity during solar cycle 24 and its consequences on Earth. One of the four VarSITI projects is called Role of the Sun and the Middle Atmosphere/Thermosphere/Ionosphere in Climate (ROSMIC) and is directed toward identifying the effects of external forcing on and predicting the effects of internal changes to the atmosphere/ionosphere. One goal of ROSMIC is to understand the impact of the Sun on the terrestrial middle atmosphere/lower thermosphere/ionosphere relative to anthropogenic forcing including coupling within the atmosphere-ionosphere system. As such, ROSMIC continues the science investigations related to understanding the geospace response to lower atmosphere variability that were carried out during CAWSES-II, using similar approaches such as observing campaigns, workshops, etc.

\section{Abbreviations}

AMBER: African Meridian B-Field Education and Research;

AWESOME: Atmospheric Weather Electromagnetic System for Observation
Modeling and Education; CAWSES: Climate and Weather of the Sun-Earth System; CERTO: coherent electromagnetic radio tomography;

CHAMP: CHAllenging Minisatellite Payload; CIR: co-rotating interaction region; CME: coronal mass ejection; COSMIC: Constellation Observing System for Meteorology; CTIPe: Coupled Thermosphere Ionosphere Plasmasphere Electrodynamics Model; CTMT: Climatological Tidal Model of the Thermosphere; D0: diurnal stationary tide of zonal wavenumber 0 ; DE2: diurnal eastward propagating tide of wavenumber 2; DE3: diurnal eastward propagating tide of wavenumber 3; DELTA: Dynamics and Energetics of the Lower Thermosphere in Aurora; DMSP: Defense Meteorological Satellite Program; DOY: day of year; DW1: diurnal westward propagating tide of wavenumber 1; DW2: diurnal westward propagating tide of wavenumber 2; DWN: Darwin; DWTS: Doppler wind and temperature sounder; DYNAMIC: dynamical atmosphere ionosphere coupling; EISCAT: European Incoherent Scatter Scientific Association; ENSO: El Niño Southern Oscillation; EPB: equatorial plasma bubble; ESA: European Space Agency; FPI: Fabry-Pérot interferometer; FDTD: finite-difference time-domain; FZA: Fortaleza; GAIA: Ground-to-Topside Model of Atmosphere and Ionosphere for Aeronomy; GCM: General Circulation Model; GITM: Global Ionosphere Thermosphere Model; GOLD: Global-scale Observations of the Limb and Disk; GNSS: Global Navigation Satellite System; GPS: global positioning system; GRACE: Gravity Recovery and Climate Experiment; GW: gravity wave; HRDI: high-resolution Doppler interferometer; HSS: high speed solar wind stream; ICON: Ionospheric Connection Explorer; IMAGE: Imager for Magnetopause-to-Aurora Global Exploration; ISR: incoherent scatter radar; ISCCP: International Satellite Cloud Climatology; LONET: LONgitudinal NETwork; LSWS: large-scale wave structure; MAGDAS: MAGnetic Data Acquisition System; MERRA: Modern-Era Retrospective Analysis for Research and Applications; MIPAS: Michelson Interferometer for Passive Atmospheric Sounding; MLS: microwave limb sounder; MLT: mesosphere lower thermosphere; MSNA: midlatitude summer nighttime anomaly; MSTID: medium-scale traveling ionospheric disturbance; NASA: National Aeronautics and Space Administration; NATION: North American Thermosphere Ionosphere Observation Network; NCAR: National Center for Atmospheric Research; NOGAPS-ALPHA: Navy Operational Global Atmospheric Prediction System - Advanced Level Physics-High Altitude; OMTIs: Optical Mesosphere Thermosphere Imagers; ONI: Oceanic Niño Index; PAM: Pameungpeuk; PFISR: Poker Flat Advanced Modular Incoherent Scatter Radar; PW: planetary wave; QBO: quasi-biannual oscillation; RENOIR: The Remote Equatorial Nighttime Observatory of Ionospheric Regions; ROSMIC: Role of the Sun and the Middle Atmosphere/Thermosphere/ lonosphere in Climate; SABER: sounding the atmosphere using broadband emission radiometry; SCOSTEP: Scientific Committee on Solar-Terrestrial Physics; SDI: scanning Doppler imager; SPW: stationary planetary wave; SSW: sudden stratospheric warming; SW4: semidiurnal westward propagating tide of wavenumber 4; TAD: traveling atmospheric disturbance; TEC: total electron content; TG4: Task Group 4; TIDI: TIMED Doppler interferometer; TIE-GCM: Thermosphere-lonosphere-Electrodynamics General Circulation Model; TIME-GCM: Thermosphere-lonosphere-MesosphereElectrodynamics General Circulation Model; TIMED: Thermosphere lonosphere Mesosphere Energetics and Dynamics; TRMM: Tropical Rainfall Measuring Mission; VarSITI: Variability of the Sun and Its Terrestrial Impact; VHF: very high frequency; WACCM-X: Whole Atmosphere Community Climate Model thermosphere extension; WAM: Whole Atmosphere Model; WINDII: wind imaging interferometer.

\section{Competing interests}

The authors declare that they have no competing interests.

\section{Authors' contributions}

JO, KS, and SG have been co-leaders of Task Group 4 (TG4) What is the geospace response to variable inputs from the lower atmosphere?' of SCOSTEP's CAWSES-II program. WW is the leader of the ROSMIC sub-program of SCOSTEP's VarSITI program and also led project 1. JM and HT organized the LONET campaign and led project 2. HF and MK led project 4. MK organized various EISCAT and PFISR campaigns. All authors read and approved the final manuscript.

\section{Acknowledgements}

JO, KS, and SG are grateful for the enthusiasm and contributions of all 250 members of TG4, especially the project leaders W. Ward, M. A. Abdu, J. Chau, J. Makela, H. Takahashi, D. Pancheva, M. Yamamoto, H. Fujiwara, 
and M. Kosch. Our special acknowledgement goes to Dr. Michi Nishioka who edited the quarterly newsletter. JM and HT thank all of the LONET and SpreadFEx-2 campaign participants. JM and HT acknowledge the COSMIC data center team who provided the TEC data. The Pameungpeuk MF radar data were provided through IUGONET under agreement of RISH, Kyoto University. JO was supported by NSF award 1139048 and NASA grants NNX11AJ13G and NNH12CF66C. KS is supported by the JSPS Grants-in-Aid for Scientific Research (20244080, 23403009, and 25247080), JSPS Core-to-Core Program, B. Asia-Africa Science Platforms, and the STEL Cooperative and IUGONET Projects from MEXT, Japan.

\section{Author details}

'Department of Physics and Astronomy, Clemson University, Clemson, SC 29634-0978, USA. ${ }^{2}$ Solar-Terrestrial Environment Laboratory, Nagoya University, Nagoya 464-8601, Japan. ${ }^{3}$ Indian Institute of Geomagnetism, Navi Mumbai 410 218, India. ${ }^{4}$ Department of Physics, University of New Brunswick, Fredericton, NB E3B 5A3, Canada. ${ }^{5}$ Faculty of Science and Technology, Seikei University, Tokyo, Japan. ${ }^{6}$ South African National Space Agency, Hermanus 7200, South Africa. 'Lancaster University, Lancaster LA1 4YB, UK. ${ }^{8}$ Currently at National Institute of Polar Research, Tachikawa, Japan. ${ }^{9}$ University of Illinois at Urbana-Champaign, Urbana, IL, USA. ${ }^{10}$ Instituto Nacional de Pesquisas espaciais, São José dos Campos, SP, Brazil.

\section{Received: 31 May 2014 Accepted: 7 December 2014}

\section{Published online: 11 February 2015}

\section{References}

Anderson C, Davies T, Conde M, Dyson P, Kosch MJ (2011) Spatial sampling of the thermospheric vertical wind field at auroral latitudes. J Geophys Res 116 A06320, doi:10.1029/2011JA016485

Anderson C, Kosch MJ, Nicolls MJ, Conde M (2013) lon-neutral coupling in the earth's thermosphere, estimate from concurrent radar and optics observations over Alaska. J Atmos Sol Terr Phys 105-106:313-324. doi:10.1016/j.jastp.2013.04.005

Anthes RA, Ector D, Hunt DC, Kuo YH, Rocken C, Schreiner WS et al (2008) The COSMIC/FORMOSAT-3 mission: early results. Bull Amer Meteor Soc 89:313-333, doi:10.1175/BAMS-89-3-313

Aruliah AL, Griffin EM, McWhiter I, Aylward AD, Ford EAK, Charalambous A et al (2004) First tristatic studies of meso-scale ion-neutral dynamics and energetic in the high-latitude upper atmosphere using co-located FPIs and EISCAT radar. Geophys Res Lett 31, L03802, doi:10.1029/2003GL018469

Aruliah AL, Griffin EM, Aylward AD, Ford EAK, Kosch MJ, Davis CJ et al (2005) First direct evidence of meso-scale variability on ion-neutral dynamics using co-located tristatic FPIs and EISCAT radar in northern Scandinavia. Ann Geophys 23:147-162

Booker HG, Wells HW (1938) Scattering of radio waves by the F-region of the ionosphere. J Geophys Res 43:249-256

Burch JL (2000) IMAGE mission overview. Space Science Reviews 91(1-14):2000

Chang LC, Ward WE, Palo SE, Du J, Wang DY, Liu HL et al (2012) Comparison of diurnal tide in models and ground-based observations during the 2005 equinox CAWSES tidal campaign. J Atmos Sol Terr Phys 78-79:19-30, doi:10.1016/j.jastp.2010.12.0104

Chang LC, Lin CH, Yue J, Liu JY, Lin JT (2013) Stationary planetary wave and nonmigrating tidal signatures in ionospheric wave 3 and wave 4 variations in 2007-2011 FORMOSAT-3/COSMIC observations. J Geophys Res Space Phys 118(10):6651-6665, doi:10.1002/jgra.50583

Chapagain NP, Makela JJ, Meriwether JW, Fisher DJ, Buriti RA, Medeiros AF (2012) Comparison of nighttime zonal neutral winds and equatorial plasma bubble drift velocities over Brazil. J Geophys Res 117, A06309, doi:10.1029/ 2012JA017620

Chau JL, Fejer BG, Goncharenko LP (2009) Quiet variability of equatorial E x B drifts during a sudden stratospheric warming event. Geophys Res Lett 36, L05101, doi:10.1029/2008GL036785

Chau JL, Aponte NA, Cabassa E, Sulzer MP, Goncharenko LP, Gonzalez SA (2010) Quiet time ionospheric variability over Arecibo during sudden stratospheric warming events. J Geophys Res 115:A00G06, doi:10.1029/2010JA015378

Chau JL, Goncharenko LP, Fejer BG, Liu HL (2012) Equatorial and low latitude ionospheric effects during sudden stratospheric warming events. Space Sci Rev 168:385-417, doi:10.1007/s11214-011-9797-5

Chen G, Xu J, Wang W, Lei J, Burns AG (2012) A comparison of the effects of CIR- and CME-induced geomagnetic activity on thermospheric densities and spacecraft orbits: case studies. J Geophys Res 117, A08315, doi:10.1029/ 2012JA017782

Chu X, Yu Z, Gardner CS, Chen C, Fong W (2011) Lidar observations of neutral Fe layers and fast gravity waves in the thermosphere $(110-155 \mathrm{~km})$ at McMurdo $\left(77.8^{\circ} \mathrm{S}, 166.7^{\circ} \mathrm{E}\right)$, Antarctica. Geophys Res Lett 38(23), L23807, doi:10.1029/ $2011 \mathrm{GL} 050016$

Cohen MB, Inan US, Paschal EW (2010) Sensitive broadband ELFNLF radio reception with the AWESOME instrument. IEEE Trans On Geosci Remote Sens 48(1):3-17, doi:10.1109/TGRS.2009.2028334

de Larquier S, Pasko VP, Stenbaek-Nielsen HC, Wilson CR, Olson JV (2010) Finite-difference time-domain modeling of infrasound from pulsating auroras and comparison with recent observations. Geophys Res Lett 37, L06804, doi:10.1029/2009GL042124

Deng Y, Fuller-Rowell TJ, Akmaev RA, Ridley AJ (2011) Impact of the altitudinal Joule heating distribution on the thermosphere. J Geophys Res 116, A05313, doi:10.1029/2010JA016019

Dungey JW (1956) Convective diffusion in the equatorial F-region. J Atmos Sol Terr Phys 9:304-310

Eastes RW, McClintock WE, Codrescu MV, Aksnes A, Anderson D, Andersson L et al (2008) Global-scale Observations of the Limb and Disk (GOLD): new observing capabilities for the ionosphere-thermosphere. In: Kintner PM, Coster AJ, Fuller-Rowell T, Mannucci J, Mendillo M, Heelis R (eds) Midlatitude ionospheric dynamics and disturbances, vol 181, Geophysical Monograph Series. American Geophysical Union, Washington DC, pp 319-326

England SL (2012) Review of the effects of non-migrating atmospheric tides on Earth's low-latitude ionosphere. Space Sci Rev 168(1-4):211-236, doi:10.1007/ s11214-011-9842-4

England SL, Immel TJ, Huba JD, Hagan ME, Maute A, DeMajistre R (2010) Modeling of multiple effects of atmospheric tides on the ionosphere: an examination of possible coupling mechanisms responsible for the longitudinal structure of the equatorial ionosphere. J Geophys Res 115 A05308, doi:10.1029/2009JA014894

Fejer JA (1964) Atmospheric tides and associated magnetic effects. Rev Geophys 2(2):275-309

Fejer BG, Olson ME, Chau JL, Stolle C, Lühr H, Goncharenko LP et al (2010) Lunar-dependent equatorial ionospheric electrodynamic effects during sudden stratospheric warmings. J Geophys Res 115:A00G03, doi:10.1029/ 2010JA015273

Forbes JM (1995) Tidal and Planetary Waves. In: Johnson RM, Killeen TL (eds) The upper mesosphere and lower thermosphere: a review of experimental and theory. geophysical monograph series, vol 87. American Geophysical Union, Washington DC, pp 67-87

Forbes JM, Russell J, Miyahara S, Zhang X, Palo S, Mlynczak M et al (2006) Troposphere-thermosphere tidal coupling as measured by the SABER instrument on TIMED during July-September 2002. J Geophys Res 111: A10S06, doi:10.1029/2005JA011492

Forbes JM, Bruinsma SL, Zhang X, Oberheide J (2009) Surface-exosphere coupling due to thermal tides. Geophys Res Lett 36, L15812, doi:10.1029/2009GL038748

Forbes JM, Zhang X, Bruinsma S, Oberheide J (2011) Sun-synchronous therma tides in exosphere temperature from CHAMP and GRACE accelerometer measurements. J Geophys Res 116, A11309, doi:10.1029/2011JA016855

Forbes JM, Zhang X, Bruinsma SL (2014) New perspectives on thermospheric tides: 2. penetration to the upper thermosphere. Earth Planets Space 66:122 doi:10.1186/1880-5981-66-122

Fritts DC, Lund TS (2011) Gravity wave influences in the thermosphere and ionosphere: observations and recent modeling. In: Abdu MA, Pancheva D (eds) Aeronomy of the Earth's atmosphere and ionosphere. IAGA Special Sopron Book Series, vol 2. Springer Science+Business Media, pp 109-130, doi:10.1007/978-94-007-0326-1_8

Fritts DC, Vadas SL, Riggin DM, Abdu MA, Batista IS, Takahashi H et al (2008) Gravity wave and tidal influences on equatorial spread $F$ based on observations during the spread F experiment (SpreadFEx). Ann Geophys 26:3235-3252, doi:10.5194/angeo-26-3235-2008

Fujitaka K, Tohmatsu T (1973) A tidal theory of the ionospheric intermediate layer. J Atmos Terr Phys 33:425-438

Fujiwara H, Nozawa S, Maeda S, Ogawa Y, Miyoshi Y, Jin H et al (2012) Polar cap thermosphere and ionosphere during the solar minimum period: EISCAT Svalbard radar observations and GCM simulations. Earth Planets Space 64:459-465, doi:10.5047/eps.2011.05.023

Fukushima D, Shiokawa K, Otsuka Y, Ogawa T (2012) Observation of equatoria nighttime medium-scale traveling ionospheric disturbances in 630-nm 
airglow images over 7 years. J Geophys Res 117, A10324, doi:10.1029/ 2012JA017758

Fuller-Rowell T, Wu F, Akmaev R, Fang TW, Araujo-Pradere E (2010) A whole atmosphere model simulation of the impact of a sudden stratospheric warming on thermosphere dynamics and electrodynamics. J Geophys Res 115:A00G08, doi:10.1029/2010JA015524

Fuller-Rowell T, Wang H, Akmaev R, Wu F, Fang TW, Iredell M et al (2011) Forecasting the dynamic and electrodynamic response to the January 2009 sudden stratospheric warming. Geophys Res Lett 38, L13102, doi:10.1029/ 2011GL047732

Fytterer T, Arras C, Hoffmann P, Jacobi C (2014) Global distribution of the migrating terdiurnal tide seen in sporadic E occurrence frequencies obtained from GPS radio occultations. Earth Planets Space 66:79, doi:10.1186/18805981-66-79

Gan Q, Du J, Ward WE, Beagley SR, Fomichev VI, Zhang S (2014) Climatology of the diurnal tides from eCMAM30 (1979 to 2010) and its comparisons with SABER. Earth Planets Space 66:103, doi:10.1186/1880-5981-66-103

Gardner LC, Schunk RW (2011) Large-scale gravity wave characteristics simulated with a high-resolution global thermosphere-ionosphere model. J Geophys Res 116, A06303, doi:10.1029/2010JA015629

Gardner L, Sojka JJ, Schunk RW, Heelis R (2012) Changes in thermospheric temperature induced by high-speed solar wind streams. J Geophys Res 117, A12303, doi:10.1029/2012JA017892

Gavrilov NM, Kshetvetskii SP (2014) Three-dimensional numerical simulation of nonlinear acoustic-gravity wave propagation from the troposphere to the thermosphere. Earth Planets Space 66:88, doi:10.1186/1880-5981-66-88

Goncharenko L, Zhang SR (2008) lonospheric signatures of sudden stratospheric warming: Ion temperature at middle latitude. Geophys Res Lett 35, L21103, doi:10.1029/2008GL035684

Goncharenko LP, Chau JL, Liu HL, Coster AJ (2010) Unexpected connections between the stratosphere and ionosphere. Geophys Res Lett 37, L10101, doi:10.1029/2010GL043125

Goncharenko LP, Hsu WW, Brum CGM, Zhang SR, Fentzke JT (2013) Wave signatures in the midlatitude ionosphere during a sudden stratospheric warming of January 2010. J Geophys Res 118:472-487, doi:10.1029/ 2012JA018251

Gordley LL, Marshall BT (2011) Doppler wind and temperature sounder (DWTS): a new approach using gas filter radiometry. J Appl Rem Sens 5:053570, doi:10.1117/1.3666048

Haagmans R, Bock R, Rider H (2013) Swarm: ESA's magnetic field mission. In: ESA communications, BR-302, September 2013, 2nd edn.. ISBN 978-92-9221-067-0

Hagan ME, Forbes JM (2002) Migrating and nonmigrating diurnal tides in the middle and upper atmosphere excited by tropospheric latent heat release. J Geophys Res 107(D24):4754, doi:10.1029/2001JD001236

Hagan ME, Forbes JM (2003) Migrating and nonmigrating semidiurnal tides in the upper atmosphere excited by tropospheric latent heat release. J Geophys Res 108(A2):1062, doi:10.1029/2002JA009466

Hagan ME, Roble RG (2001) Modeling the diurnal tidal variability with the National Center for Atmospheric Research thermosphere-ionospheremesosphere-electrodynamics general circulation model. J Geophys Res 106 (A11):24,869-24,882

Hagan ME, Maute Al, Roble RG, Richmond AD, Immel TJ, England SL (2007) Connections between deep tropical clouds and the Earth's ionosphere. Geophys Res Lett 34, L20109, doi:10.1029/2007GL030142

Hagan ME, Maute Al, Roble RG (2009) Tropospheric tidal effects on the middle and upper atmosphere. J Geophys Res 114, A01302, doi:10.1029/ 2008JA013637

Haldoupis C (2011) Midlatitude sporadic E. A typical paradigm of atmosphereionosphere coupling. Space Sci Rev 168:441-461, doi:10.1007/s11214-0119786-8

Häusler K, Oberheide J, Lühr H, Koppmann R (2013) The geospace response to nonmigrating tides. In: Lübken FJ (ed) Climate and Weather of the Sun-Earth System (CAWSES), Springer Atmospheric Sciences Series, vol 21., pp 481-504. ISBN 978-94-007-4348-9

Hines CO (1960) Internal gravity waves at ionospheric heights. Can J Phys 38 (11):1441-1481

Immel TJ, Sagawa E, England SL, Henderson SB, Hagan ME, Mende SB et al (2006) Control of equatorial ionospheric morphology by atmospheric tides. Geophys Res Lett 33, L15108, doi:10.1029/2006GL026161

International CAWSES-II Symposium (2014). Special Issue in Earth Planets Space 66. In: Yamamoto M, Shiokawa K, Nakamura T, Gopalswamy N (eds)
Jin H, Miyoshi Y, Fujiwara H, Shinagawa H, Terada K, Terada N et al (2011) Vertical connection from the tropospheric activities to the ionospheric longitudinal structure simulated by a new Earth's whole atmosphere-ionosphere coupled model. J Geophys Res 116, A01316, doi:10.1029/2010JA015925

Jin H, Miyoshi Y, Pancheva D, Mukhtarov P, Fujiwara H, Shinagawa H (2012) Response of migrating tides to the stratospheric sudden warming in 2009 and their effects on the ionosphere studied by a whole atmosphereionosphere model GAIA with COSMIC and TIMED/SABER observations. J Geophys Res 117(A10), A10323, doi:10.1029/2012JA017650

Jones M Jr, Forbes JM, Hagan ME, Maute A (2013) Non-migrating tides in the ionosphere-thermosphere: in situ versus tropospheric sources. J Geophys Res Space Phys 118(5):2438-2451, doi:10.1002/jgra.50257

Kishore Kumar G, Singer W, Oberheide J, Grieger N, Batista PP, Riggin DM et al (2013) Diurnal tides at low latitudes: radar, satellite, and model results. J Atmos Sol Terr Phys 118:96-105, doi:10.1016/j.jastp.2013.07.005

Kosch MJ, Anderson C, Makarevich RA, Carter BA, Fiori RAD, Conde M et al (2010) First $\mathrm{E}$ region observations of mesoscale neutral wind interaction with auroral arcs. J Geophys Res 115, A02303, doi:10.1029/2009JA014697

Kosch M, Yiu I, Anderson C, Tsuda T, Ogawa Y, Nozawa S et al (2011) Meso-scale observations of Joule heating near an auroral arc and ion-neutral collision frequency in the polar cap E-region. J Geophys Res 116, A05321, doi:10.1029/ 2010JA016015

Kubota M, Conde M, Ishii M, Murayama Y, Jin H (2011) Characteristics of nighttime MSTID/AGW observed over Alaska. J Geophys Res 116, A05307, doi:10.1029/2010JA016212

Kurihara J, Oyama S, Nozawa S, Tsuda TT, Fujii R, Ogawa Y et al (2009) Temperature enhancements and vertical winds in the lower thermosphere associated with auroral heating during the DELTA campaign. I Geophys Res 114, A12306, doi:10.1029/2009JA014392

Laskar Fl, Pallamraju D, Veenadhari B (2014) Vertical coupling of atmospheres: dependence on strength of sudden stratospheric warming and solar activity. Earth Planets Space 66:94, doi:10.1186/1880-5981-66-94

Lastovicka J (2006) Forcing of the ionosphere by waves from below. J Atmos Sol Terr Phys 68:479-497, doi:10.1016/j.jastp.2005.01.018

Lei J, Thayer JP, Wang W, McPherron RL (2011) Impact of CIR storms on thermosphere density variability during the solar minimum of 2008. Sol Phys 274:427-437, doi:10.1007/s11207-010-9563-y

Lieberman RS, Oberheide J, Gordley LL, Marshall BT (2012) Recovery of planetaryscale waves in stratospheric, mesospheric, and lower thermospheric winds and temperature from the Doppler wind and temperature sounder. J Appl Remote Sens 6(1):063570, doi:101117/1.JRS.6.063570

Lieberman RS, Oberheide J, Talaat ER (2013a) Nonmigrating diurnal tides observed in global thermospheric winds. J Geophys Res Space Phys 118:7384-7397, doi:10.1002/2013JA018975

Lieberman RS, Riggin DM, Siskind DE (2013b) Stationary waves in the wintertime mesosphere: evidence for gravity wave filtering by stratospheric planetary waves. J Geophys Res Atmos 118:3139-3149, doi:10.1002/jgrd.50319

Lin CH, Wang W, Hagan ME, Hsiao CC, Immel TJ, Hsu ML et al (2007) Plausible effect of atmospheric tides on the equatorial ionosphere observed by the FORMOSAT-3/COSMIC: three-dimensional electron density structures. Geophys Res Lett 34, L11112, doi:10.1029/2007GL029265

Liu HL, Roble RG (2002) A study of a self-generated stratospheric sudden warming and its mesospheric/lower thermospheric impacts using the coupled TIMEGCM/ CCM3. J Geophys Res 107(D23):1-18, doi:10.1029/2001JD001533

Liu H, Yamamoto M (2011) Weakening of the mid-latitude summer nighttime anomaly during geomagnetic storms. Earth Planets Space 63:371-375, doi:10.5047/eps.2010.11.012

Liu H, Yamamoto M, Lühr H (2009) Wave-4 pattern of the equatorial mass density anomaly: a thermospheric signature of tropical deep convection. Geophys Res Lett 36, L18104, doi:10.1029/2009GL039865

Liu G, Immel TJ, England SL, Kumar KK, Ramkumar G (2010a) Temporal modulations of the longitudinal structure in F2 peak height in the equatorial ionosphere as observed by COSMIC. J Geophys Res 115, A04303, doi:10.1029/ 2009JA014829

Liu G, Immel TJ, England SL, Kumar KK, Ramkumar G (2010b) Temporal modulation of the four-peaked longitudinal structure of the equatorial ionosphere by the 2 day planetary wave. J Geophys Res 115, A12338, do::10.1029/2010JA016071

Liu HL, Foster BT, Hagan ME, McInerney JM, Maute A, Qian L et al (2010c) Thermosphere extension of the whole atmosphere community climate model. J Geophys Res 115, A12301, doi:10.1029/2010JA015586 
Liu HL, Wang W, Richmond AD, Roble RG (2010d) lonospheric variability due to planetary waves and tides for solar minimum conditions. J Geophys Res 115 : A00G01, doi:10.1029/2009JA015188

Liu H, Jin H, Miyoshi Y, Fujiwara H, Shinagawa H (2013a) Upper atmosphere response to stratosphere sudden warming: local time and height dependence simulated by GAIA model. Geophys Res Lett 40:635-640, doi:10.1002/grl.50146

Liu HL, Yudin VA, Roble RG (2013b) Day-to-day ionospheric variability due to lower atmosphere perturbations. Geophys Res Lett 40:665-670, doi:10.1002/ grl.50125

Lühr H, Rother M, Kohler W, Ritter P, Grunwaldt L (2004) Thermospheric up-welling in the cusp region: evidence from CHAMP observations. Geophys Res Lett 31(6), L06805, doi:10.1029/2003GL019314

Lühr H, Park J, Ritter P, Liu H (2012) In-situ CHAMP observations of the ionosphere-thermosphere coupling. Space Sci Rev 168(1-4):237-260, doi:10.1007/s11214-011-9798-4

Makela JJ, Meriwether JW, Lima JP, Miller ES, Armstrong SJ (2009) The remote equatorial nighttime observatory of ionospheric regions project and the international heliospherical year. Earth Moon Planets 104(1-4):211-226, doi:10.1007/s11038-008-9289-0

Makela JJ, Vadas SL, Muryanto R, Duly T, Crowley G (2010) Periodic spacing between consecutive equatorial plasma bubbles. Geophys Res Lett 37, L14103, doi:10.1029/2010GL043968

Makela JJ, Lognonné P, Hébert H, Gehrels T, Rolland L, Allgeyer S et al (2011) Imaging and modeling of the ionospheric airglow response over Hawaii to the tsunami generated by the Tohoku earthquake of 11 March 2011. Geophys Res Lett 38:L00G02, doi:10.1029/2011GL047860

Makela JJ, Meriwether JW, Ridley AJ, Ciocca M, Castelaz MW (2012) Large-scale measurements of thermospheric dynamics with a multisite Fabry-Pérot interferometer network: overview of plans and results from midlatitude measurements. Int J Geophys Article ID Article ID 872140, doi:10.1155/2012/ 872140

Makela JJ, Fisher DJ, Meriwether JW, Buriti RA, Medeiros AF (2013) Near-continual ground-based nighttime observations of thermospheric neutral winds and temperatures over equatorial Brazil from 2009 to 2012. J Atmos Sol Terr Phys 103:94-102, doi:10.1016/j.jastp.2012.11.019

Matsumura M, Saito A, leymori T, Shinagawa H, Tsugawa T, Otsuka Y et al (2011) Numerical simulations of atmospheric waves excited 2011 off the Pacific coast of Tohoku earthquake. Earth Planets Space 63(7):885-889, doi:10.5047/ eps.2011.07.015

Maute A, Richmond AD, Roble RG (2012) Sources of low-latitude ionospheric ExB drifts and their variability. J Geophys Res 117, A06312, doi:10.1029/ 2011JA017502

Meriwether JW, Makela JJ, Fisher DJ, Buriti RA, Medeiros AF, Akmaev RA et al (2013) Comparisons of thermospheric wind and temperature measurements in equatorial brazil to whole atmosphere model predictions. J Atmos Sol Terr Phys 103:103-112, doi:10.1016/j.jastp.2013.04.002

Meriwether JW, Makela JJ, Ridley A, Hampton DL, Gerrard A, Ciocca M et al (2014) Observations from a network of Fabry-Pérot interferometers and the HOPE-A probe. Paper presented at AGU Chapman Conference on Magnetosphere-lonosphere Coupling in the Solar System, Yosemite National Park, CA

Mukhtarov P, Pancheva D, Andonov B (2010) Climatology of the stationary planetary waves seen in the SABER/TIMED temperatures (2002-2007). J Geophys Res 115, A06315, doi:10.1029/2009JA015156

Narayanan VL, Sau S, Gurubaran S, Shiokawa K, Balan N, Emperumal K et al (2014) A statistical study of satellite traces and subsequent evolution of equatorial spread $\mathrm{F}$ based on ionosonde observations over dip equatorial site Tirunelveli, India. Earth Planets Space 66:160

National Research Council (2013) Solar and space physics: a science for a technological society. The National Academies Press, Washington DC. ISBN 978-0-309-16428-3

Nguyen V, Palo SE (2013) Technique to produce daily estimates of the migrating diurnal tide using TIMED/SABER and EOS Aura/MLS. J Atmos Sol Terr Phys 105-106:39-53, doi:10.1016/j.jastp.2013.07.008

Nicolls MJ, Heinselman CJ (2007) Three-dimensional measurements of traveling ionospheric disturbances with the Poker Flat Incoherent Scatter Radar. Geophys Res Lett 34, L21104, doi:10.1029/2007GL031506

Nishioka M, Tsugawa T, Kubota M, Ishii M (2013) Concentric waves and shortperiod oscillations observed in the ionosphere after the 2013 Moore EF5tornado. Geophys Res Lett 40:5581-5586, doi:10.1002/2013GL057963
Oberheide J, Forbes JM (2008) Thermospheric nitric oxide variability induced by nonmigrating tides. Geophys Res Lett 35, L16814, doi:10.1029/2008GL034825

Oberheide J, Hagan ME, Roble RG, Offermann D (2002) Sources of nonmigrating tides in the tropical middle atmosphere. J Geophys Res 107(D21):4567, doi:10.1029/2002JD002220

Oberheide J, Liu HL, Gusev O, Offermann D (2006a) Mesospheric surf zone and temperature inversion layers in early November 1994. J Atmos Sol Terr Phys 68(15):1752-1763, doi:10.1016/j.jastp.2005.11.013

Oberheide J, Wu Q, Killeen TL, Hagan ME, Roble RG (2006b) Diurnal nonmigrating tides from TIMED Doppler interferometer wind data: monthly climatologies and seasonal variations. J Geophys Res 111:A10S03, doi:10.1029/2005JA011491

Oberheide J, Forbes JM, Häusler K, Wu Q, Bruinsma SL (2009) Tropospheric tides from 80-400 km: propagation, inter-annual variability and solar cycle effects. J Geophys Res 114:D00I05, doi:10.1029/2009JD012388

Oberheide J, Forbes JM, Zhang X, Bruinsma SL (2011a) Climatology of upward propagating diurnal and semidiurnal tides in the thermosphere. J Geophys Res 116, A11306, doi:10.1029/2011JA016784

Oberheide J, Forbes JM, Zhang X, Bruinsma SL (2011b) Wave-driven variability in the ionosphere-thermosphere-mesosphere system from TIMED observations: what contributes to the 'wave-4'? J Geophys Res 116, A01306, doi:10.1029/ 2010JA015911

Oberheide J, Mlynczak MG, Mosso CN, Schroeder BM, Funke B, Maute A (2013) Impact of tropospheric tides on the nitric oxide $5.3 \mu \mathrm{m}$ infrared cooling of the low-latitude thermosphere during solar minimum conditions. J Geophys Res 118:7283-7293, doi:10.1002/2013JA019278

Otsuka Y, Shiokawa K, Ogawa T (2012) Disappearance of equatorial plasma bubble after interaction with mid-latitude medium-scale traveling ionospheric disturbance. Geophys Res Lett 39, L14105, doi:10.1029/ 2012GL052286

Otsuka Y, Suzuki K, Nakagawa S, Nishioka M, Shiokawa K, Tsugawa T (2013) GPS observations of medium-scale traveling ionospheric disturbances over Europe. Ann Geophys 31:163-172, doi:10.5194/angeo-31-163-2013

Oyama S, Watkins BJ (2012) Generation of atmospheric gravity waves in the polar thermosphere in response to auroral activity. Space Sci Rev 168(1-4):463-473, doi:10.1007/s11214-011-9847-z

Oyama S, Tsuda TT, Sakanoi T, Obuchi Y, Asamura K, Hirahara M et al (2009) Spatial evolution of frictional heating and the predicted thermospheric-wind effects in the vicinity of an auroral arc measured with the Sondrestrom incoherent-scatter radar and the Reimei satellite. J Geophys Res 114, A07311, doi:10.1029/2009JA014091

Oyama S, Shiokawa K, Kurihara J, Tsuda TT, Nozawa S, Ogawa Y et al (2010) Lower-thermospheric wind fluctuations measured with an FPI during pulsating aurora at Tromso, Norway. Ann Geophys 28:1847-1857, doi:10.5194/angeo-28-1847-2010

Pancheva D, Mukhtarov P (2011) Stratospheric warmings; the atmosphereionosphere coupling paradigm. J Atmos Sol Terr Phys 73:1697-1702, doi:10.1016/j.jastp.2011.03.006

Pancheva D, Mukhtarov P (2012) Planetary wave coupling of the atmosphereionosphere system during the Northern winter of 2008/2009. Adv Space Res 50:1189-1203, doi:10.1016/j.asr.2012.06.023

Pancheva D, Mukhtarov P, Andonov B, Forbes JM (2010) Global distribution and climatological features of the 5-6-day planetary waves seen in the SABER/ TIMED temperatures (2002-2007). J Atmos Sol Terr Phys 72:26-37, doi:10.1016/j.jastp.2009.10.005

Park J, Lühr H, Kunze M, Fejer BG, Min KW (2012) Effect of sudden stratospheric warming on lunar tidal modulation of the equatorial electrojet. J Geophys Res 117, A03306, doi:10.1029/2011JA017351

Paulino I, Takahashi H, Medeiros AF, Wrasse CM, Buriti RA, Sobral JHA et al (2011) Mesospheric gravity waves and ionospheric plasma bubbles observed during the COPEX campaign. J Atmos Sol Terr Phys 73:1575-1580, doi:10.1016/j. jastp.2010.12.004

Pedatella NM, Forbes JM (2009a) Interannual variability in the longitudinal structure of the low-latitude ionosphere due to the El Niño - Southern Oscillation. J Geophys Res 114, A12316, doi:10.1029/2009JA014494

Pedatella NM, Forbes JM (2009b) Modulation of the equatorial F-region by the quasi-16-day planetary wave. Geophys Res Lett 36, L09105, doi:10.1029/ 2009GL037809

Pedatella NM, Forbes JM (2011) Electrodynamic response of the ionosphere to high-speed solar wind streams. J Geophys Res 116, A12310, doi:10.1029/ 2011JA017050 
Pedatella NM, Liu HL (2012) Tidal variability in the mesosphere and lower thermosphere due to the El Niño - Southern Oscillation. Geophys Res Lett 39, L19802, doi:10.1029/2012GL053383

Pedatella NM, Liu HL, Sassi F, Lei J, Chau JL, Zhang X (2014) lonosphere variability during the 2009 SSW: influence of the lunar semidiurnal tide and mechanisms producing electron density variability. J Geophys Res 119 (in press), doi:10.1002/2014JA019849

Perkins F (1973) Spread F and ionospheric currents. J Geophys Res 78:218-226

Qian L, Solomon SC, Mlynczak MG (2010) Model simulation of thermospheric response to recurrent geomagnetic forcing. J Geophys Res 115, A10301, doi:10.1029/2010JA015309

Reigber C, Lühr H, Grunwaldt L, Förste C, König R, Massmann H et al (2006) CHAMP Mission 5 Years in Orbit. In: Flury J, Reigber C, Rothacher M, Boedecker G, Schriber U (eds) Observation of the Earth System from Space, Springer, pp 3-15, doi:10.1007/3-540-29522-4_1.

Ritter P, Lühr H, Doornbos E (2010) Substorm-related thermospheric density and wind disturbances derived from CHAMP observations. Ann Geophys 28:1207-1220, doi:10.5194/angeo-28-1207-2010

Sagawa E, Immel TJ, Frey HU, Mende SB (2005) Longitudinal structure of the equatorial anomaly in the nighttime ionosphere observed by IMAGE/FUV. J Geophys Res 110, A11302, doi:10.1029/2004JA010848

Shiokawa K, Otsuka Y, Ogawa T (2009) Propagation characteristics of nighttime mesospheric and thermospheric waves observed by optical mesosphere thermosphere imagers at middle and low latitudes. Earth Planets Space 61:479-491

Shiokawa K, Mori M, Otsuka Y, Oyama S, Nozawa S (2012) Motion of high-latitude nighttime medium-scale traveling ionospheric disturbances associated with auroral brightening. J Geophys Res 117, A10316, doi:10.1029/2012JA017928

Shiokawa K, Mori M, Otsuka Y, Oyama S, Nozawa S, Suzuki S et al (2013) Observation of nighttime medium-scale travelling ionospheric disturbances by two 630-nm airglow imagers near the auroral zone. J Atmos Sol Terr Phys 103:184-194, doi:10.1016/j.jastp.2013.03.024

Shiokawa K, Otsuka Y, Lynn KJ, Wilkinson P, Tsugawa T (2104) Airglow-imaging observation of plasma bubble disappearance at geomagnetically conjugate points. Earth Planets Space (in press)

Smith AK (2003) The origin of stationary waves in upper mesospheric winds. J Atmos Sci 54:2129-2145, doi:10.1175/1520-0469(2003)060<3033: TOOSPW $>2.0 . \mathrm{CO}: 2$

Smith SM, Vadas SL, Baggaley WJ, Hernandez G, Baumgardner J (2013) Gravity wave coupling between the mesosphere and thermosphere over New Zealand. J Geophys Res Space Phys 118(5):2694-2707, doi:10.1002/jgra.50263

Stening RJ (2011) Lunar tide in the equatorial electrojet in relation to stratospheric warmings. J Geophys Res 116, A12315, doi:10.1029/2011JA017047

Stewart B (1882) Terrestrial magnetism. Encyclopedia Britannica, vol 16, 9th edn. pp 159-184

Swarm Science Data Processing and Products - the Swarm Satellite Constellation Application and Research Facility (2013). In: Special issue in Earth Planets Space 65(11):1185-1398

Takahashi H, Taylor MJ, Pautet PD, Medeiros AF, Gobbi D, Wrasse CM et al (2009) Simultaneous observation of ionospheric plasma bubbles and mesospheric gravity waves during the SpreadFEx Campaign. Ann Geophys 27:1477-1487

Takahashi H, Costa S, Otsuka Y, Shiokawa K, Monico JFG, Paula E et al (2014) Diagnostics of equatorial and low latitude ionosphere by TEC mapping over Brazil. Adv Space Res 54(3):385-394, doi:10.1016/j.asr.2014.01.032

Taori A, Makela JJ, Taylor M (2010) Mesospheric wave signatures and equatorial plasma bubbles: a case study. J Geophys Res 115, A06302, doi:10.1029/ 2009JA015088

Taori A, Patra AK, Joshi LM (2011) Gravity wave seeding of equatorial plasma bubbles: an investigation with simultaneous $\mathrm{F}$ region, E region, and middle atmospheric measurements. J Geophys Res 116, A05310, doi:10.1029/ 2010JA016229

Tapley BD, Bettadpur S, Watkins M, Reigber C (2004) The gravity recovery and climate experiment: mission overview and early results. Geophys Res Lett 31, L09607, doi:10.1029/2004GL019920

Thampi SV, Yamamoto M, Tsunoda RT, Otsuka Y, Tsugawa T, Uemoto J et al (2009) First observations of large-scale wave structure and equatorial spread F using CERTO radio beacon on the C/NOFS satellite. Geophys Res Lett 36, L18111, doi:10.1029/2009GL039887

Thayer JP, Lei J, Forbes JM, Sutton EK, Nerem RS (2008) Thermospheric density oscillations due to periodic solar wind high-speed streams. J Geophys Res 113, A06307, doi:10.1029/2008JA013190
Tsuda T, Nozawa S, Kawahara TD, Kawabata T, Saito N, Wada S et al (2013) Decrease in sodium density observed during auroral particle precipitation over Tromso, Norway. Geophys Res Lett 40:4486-4490, doi:10.1002/ grl.50897

Tsugawa T, Saito A, Otsuka Y, Nishioka M, Maruyama T, Kato H et al (2011) Ionospheric disturbances detected by GPS total electron content observation after the 2011 off the Pacific coast of Tohoku earthquake. Earth Planets Space 63:875-879, doi:10.5047/eps.2011.06.035

Tsunoda RT (2005) On the enigma of day-to-day variability in equatorial spread $\mathrm{F}$. Geophys Res Lett 32, L08103, doi:10.1029/2005GL022512

Tsunoda RT, Bubenik DM, Thampi SV, Yamamoto M (2010) On large-scale wave structure and equatorial spread $F$ without a post-sunset rise of the $F$ layer. Geophys Res Lett 37, L07105, doi:10.1029/2009GL042357

Tsunoda RT, Yamamoto M, Tsugawa T, Hoang TL, Tulasi Ram S, Thampi SV et al (2011) On seeding, large-scale wave structure, equatorial spread F, and scintillations over Vietnam. Geophys Res Lett 38, L20102, doi:10.1029/ 2011 GL049173

Vadas SL, Crowley G (2010) Source of the traveling ionospheric disturbances observed by the ionospheric TIDDBIT sounder near Wallops Island on 30 October 2007. J Geophys Res 115, A07324, doi:10.1029/2009JA015053

Vadas SL, Liu HL (2009) The generation of large-scale gravity waves and neutral winds in the thermosphere from the dissipation of convectively-generated gravity waves. J Geophys Res 114, A10310, doi:10.1029/2009JA014108

Vadas SL, Liu HL (2013) Numerical modeling of the large-scale neutral and plasma responses to the body forces created by the dissipation of gravity waves from 6 h of deep convection in Brazil. J Geophys Res Space Phys 118:2593-2617, doi:10.1002/jgra.50249

Verbanac G, Vršnak B, Živković S, Hojsak T, Veronig AM, Temmer M (2011) Solar wind high-speed streams and related geomagnetic activity in the declining phase of solar cycle 23. Astro Astrophys 533, doi:10.1051/0004-6361/ 201116615

Vickers H, Kosch MJ, Sutton E, Ogawa Y, La Hoz C (2013) Thermospheric atomic oxygen density estimates using the EISCAT Svalbard radar. J Geophys Res 118:1319-1330, doi:10.1002/jgra.50169

Vickers H, Kosch MJ, Sutton E, Bjoland L, Ogawa Y, La Hoz C (2014) A solar cycle of upper thermosphere density observations from the EISCAT Svalbard radar. J Geophys Res Space Physics 119:6833-6845, doi:10.1002/2014JA019885

Wang H, Akmaev RA, Fang TW, Fuller-Rowell TJ, Wu F, Maruyama N et al (2014) First forecast of a sudden stratospheric warming with a coupled whole-atmosphere/ionosphere model IDEA. J Geophys Res Space Phys 119:2079-2089, doi:10.1002/2013JA019481

Wannberg UG, Andersson H, Behlke R, Belyey V, Bergqvist P, Borg J et al (2010) EISCAT_3D: a next-generation European radar system for upper-atmosphere and geospace research. Radio Sci Bull 332:75-88

Ward WE, Oberheide J, Goncharenko LP, Nakamura T, Hoffmann P, Singer W et al (2010) On the consistency of model, ground-based, and satellite observations of tidal signatures: Initial results from the CAWSES tidal campaigns. J Geophys Res 115, D07107, doi:10.1029/2009JD012593

Warner K, Oberheide J (2014) Nonmigrating tidal heating and MLT tidal wind variability due to the El Niño - Southern Oscillation. J Geophys Res Atmospheres 119:1249-1265, doi:10.1002/2013JD020407

Xu J, Smith AK, Wang W, Jiang G, Yuan W, Gao H et al (2013) An observational and theoretical study of the longitudinal variation in neutral temperature induced by aurora heating in the lower thermosphere. J Geophys Res Space Phys 118:7410-7425, doi:10.1002/2013JA019144

Yamazaki Y, Richmond AD, Yumoto K (2012) Stratospheric warmings and the geomagnetic lunar tide: 1958-2007. J Geophys Res 117, A04301, doi:10.1029/ 2012JA017514

Yee JH, Cameron GE, Kusnierkiewicz DY (1999) Overview of TIMED. Proc SPIE 3756:244, doi:10.1117/12.366378

Yiğit E, Medvedev AS, Aylward AS, Ridley AA, Harris MJ, Moldwin MB et al (2012) Dynamical effects of internal gravity waves in the equinoctial thermosphere. J Atmos Sol Terr Phys 90-91:104-116, doi:10.1016/j. jastp.2011.11.014

Yiğit E, Medvedev AS, England SL, Immel TJ (2014) Simulated variability of the high-latitude thermosphere induced by small-scale gravity waves during a sudden stratospheric warming. J Geophys Res Space Phys 119:357-365, doi:10.1002/2013JA019283

Yizengaw E, Moldwin MB (2009) African Meridian B-Field Education and Research (AMBER) array. Earth Moon Planets 104(1-4):237-246, doi:10.1007/s11038$008-9287-2$ 
Yokoyama T, Hysell DL, Otsuka Y, Yamamoto M (2009) Three-dimensional simulation of the coupled Perkins and Es-layer instabilities in the nighttime midlatitude ionosphere. J Geophys Res 114, A03308, doi:10.1029/ 2008JA013789

Yumoto K (2011) Update on MAGDAS activities around the globe during ISWI. 2011 IEEE International Conference on Space Science and Communication: Towards Exploring the Equatorial Phenomena' IconSpace 2011 Proc art. no. 6015894, 254-257

Submit your manuscript to a SpringerOpen ${ }^{\circ}$ journal and benefit from:

- Convenient online submission

- Rigorous peer review

- Immediate publication on acceptance

- Open access: articles freely available online

- High visibility within the field

- Retaining the copyright to your article

Submit your next manuscript at $\boldsymbol{\nabla}$ springeropen.com 